\title{
Fluoride Salt-Cooled High-Temperature Demonstration Reactor Point Design
}

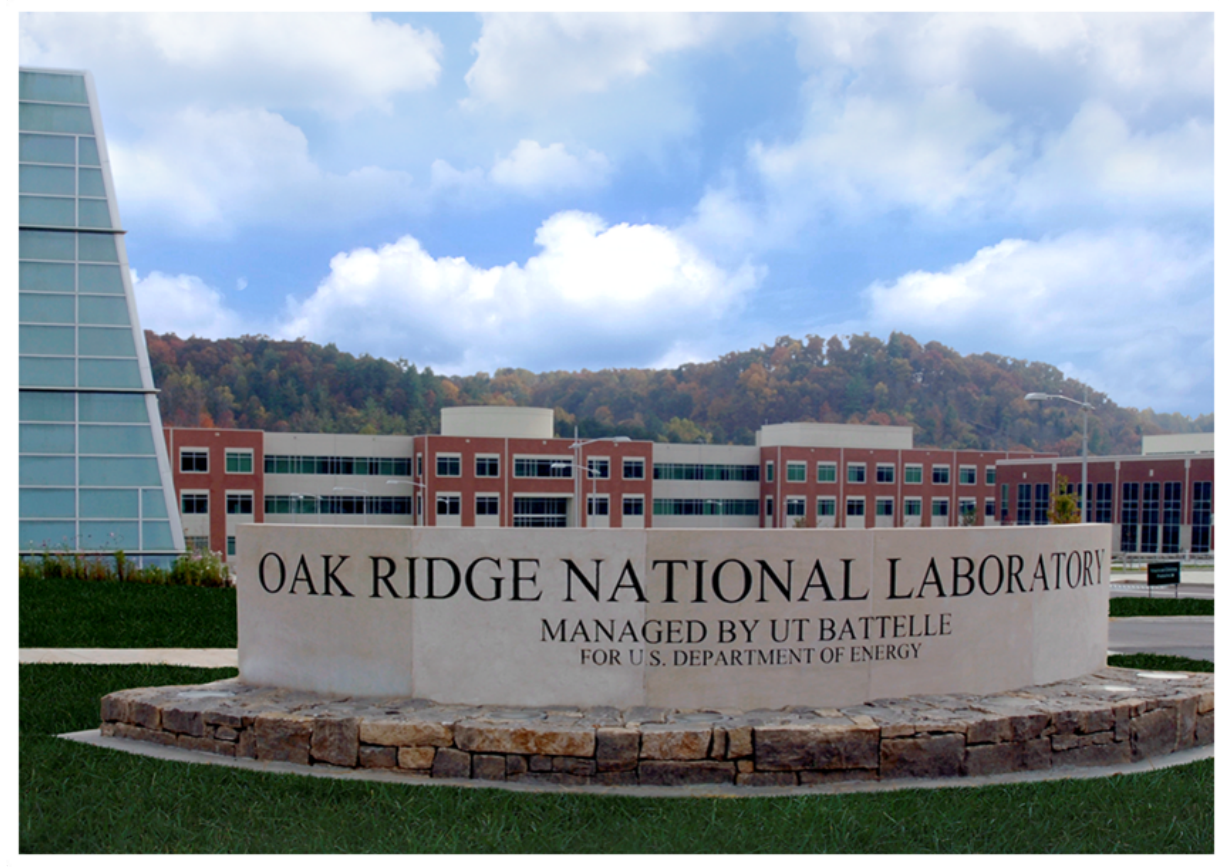

Approved for public release. Distribution is unlimited.
A. Qualls
N. Brown
B. Betzler
J. Carbajo
M. Greenwood
R. Hale
T. Harrison
J. Powers
K. Robb
J. Terrell
A. Wysocki

February 2016 


\section{DOCUMENT AVAILABILITY}

Reports produced after January 1, 1996, are generally available free via US Department of Energy (DOE) SciTech Connect.

Website http://www.osti.gov/scitech/

Reports produced before January 1, 1996, may be purchased by members of the public from the following source:

National Technical Information Service

5285 Port Royal Road

Springfield, VA 22161

Telephone 703-605-6000 (1-800-553-6847)

TDD 703-487-4639

Fax 703-605-6900

E-mailinfo@ntis.gov

Website http://www.ntis.gov/help/ordermethods.aspx

Reports are available to DOE employees, DOE contractors, Energy Technology Data Exchange representatives, and International Nuclear Information System representatives from the following source:

Office of Scientific and Technical Information

PO Box 62

Oak Ridge, TN 37831

Telephone 865-576-8401

Fax 865-576-5728

E-mail reports@osti.gov

Website http://www.osti.gov/contact.html

This report was prepared as an account of work sponsored by an agency of the United States Government. Neither the United States Government nor any agency thereof, nor any of their employees, makes any warranty, express or implied, or assumes any legal liability or responsibility for the accuracy, completeness, or usefulness of any information, apparatus, product, or process disclosed, or represents that its use would not infringe privately owned rights. Reference herein to any specific commercial product, process, or service by trade name, trademark, manufacturer, or otherwise, does not necessarily constitute or imply its endorsement, recommendation, or favoring by the United States Government or any agency thereof. The views and opinions of authors expressed herein do not necessarily state or reflect those of the United States Government or any agency thereof. 
Reactor and Nuclear Systems Division

\title{
FLUORIDE SALT-COOLED HIGH-TEMPERATURE DEMONSTRATION REACTOR POINT DESIGN
}

\author{
A. Qualls \\ N. Brown \\ B. Betzler \\ J. Carbajo \\ M. Greenwood \\ R. Hale \\ T. Harrison \\ J. Powers \\ K. Robb \\ J. Terrell \\ A. Wysocki
}

Date Published: February 2016

Prepared by

OAK RIDGE NATIONAL LABORATORY

Oak Ridge, TN 37831-6283

managed by

UT-BATTELLE, LLC

for the

US DEPARTMENT OF ENERGY

under contract DE-AC05-00OR22725 



\section{CONTENTS}

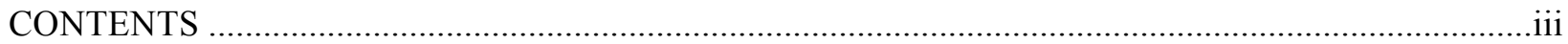

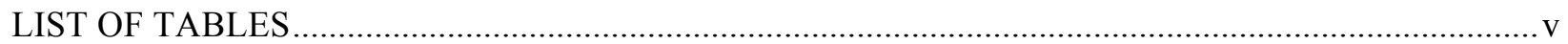

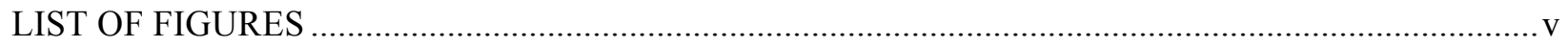

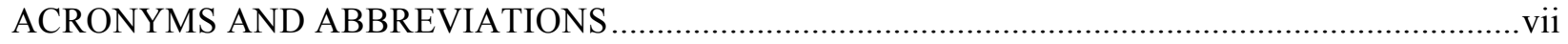

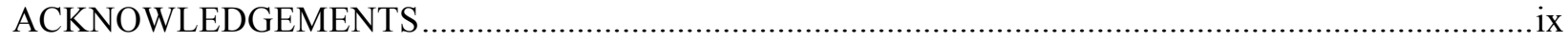

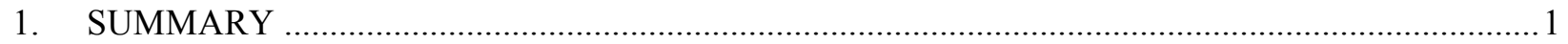

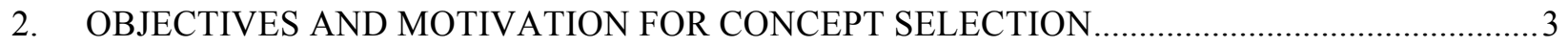

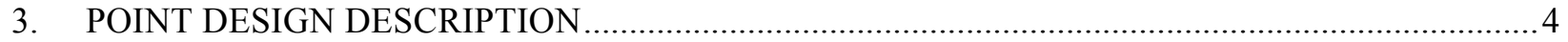

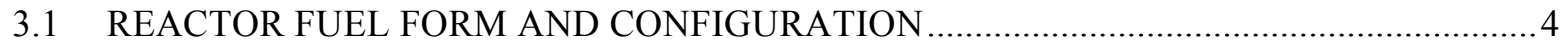

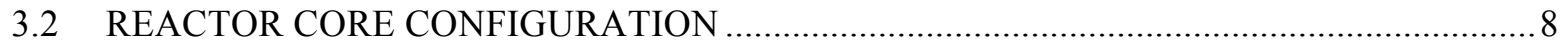

3.3 PRIMARY SYSTEM SALT COOLANT AND TRITIUM MANAGEMENT …................... 12

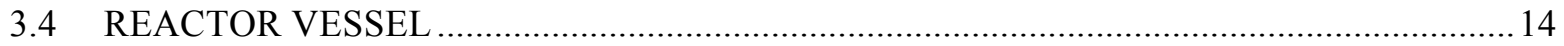

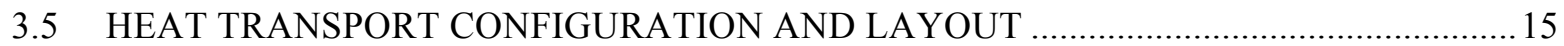

3.6 REACTOR BUILDING AND AUXILIARY REACTOR SYSTEMS ................................ 17

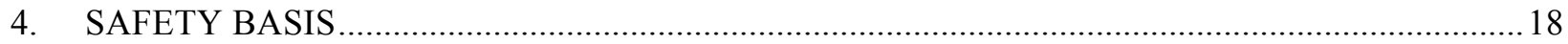

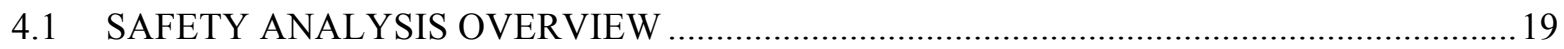

4.2 INSTRUMENTATION AND CONTROL DRIVE MECHANISMS …................................ 21

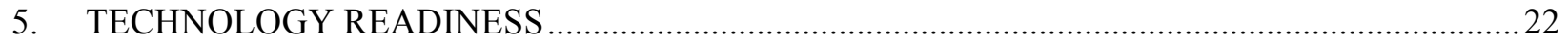

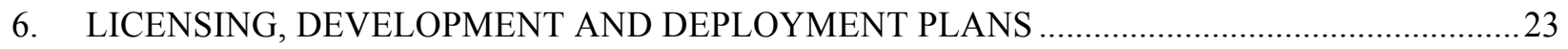

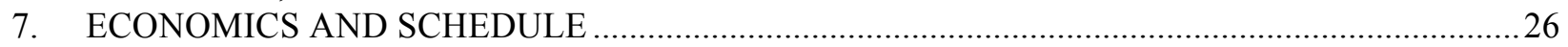

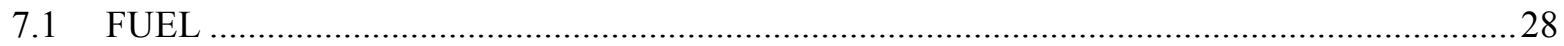

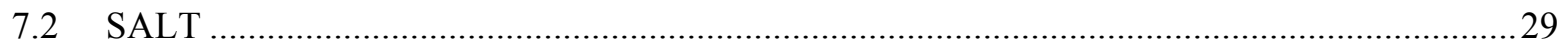

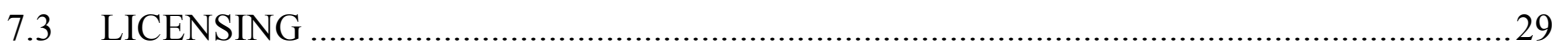

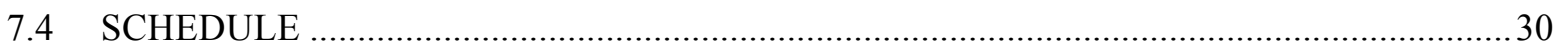

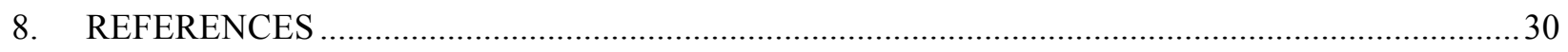





\section{LIST OF TABLES}

Table 1. Example fuel cycle performance parameters of the FHR DR …..............................................9

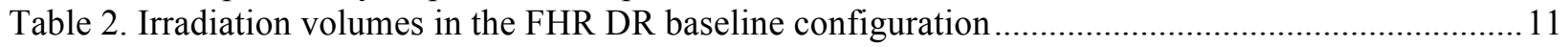

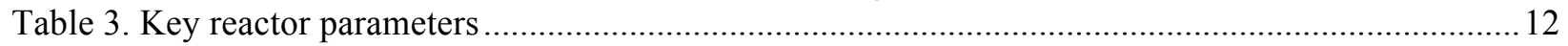

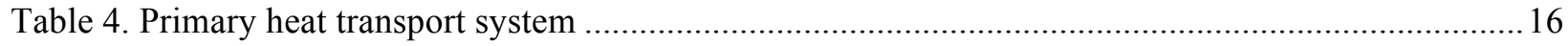

Table 5. Nominal scoping cost estimates for FHR DR deployment without contingency .........................22

Table 6. Cost estimates for salts $(99.995 \%$ enriched lithium) ….............................................................29

\section{LIST OF FIGURES}

Fig. 1. FHR demonstration reactor: isometric view (left) and planar drawing (right). .............................2

Fig. 2. Elevation view of the FHR DR showing the reactor core within the vessel................................. 4

Fig. 3. Notional alternative fuel types in the FHR DR form factor: directly cooled compacts (left)

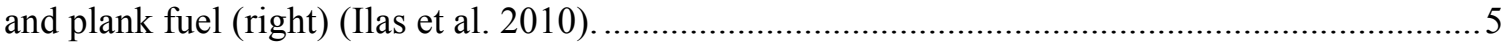

Fig. 4. FHR DR estimated fuel fabrication and performance indicators. ............................................6

Fig. 5. Peak burnup, temperature, and fast fluence. …......................................................................... 6

Fig. 6. Radial core layout of the neutronic model (left) and isometric view showing core components

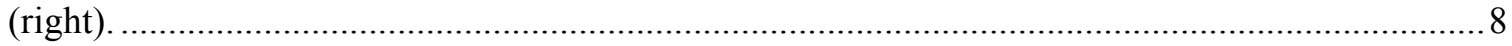

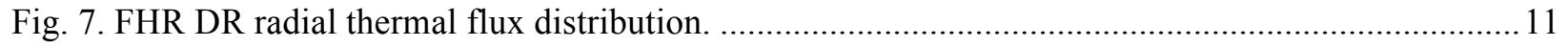

Fig. 8. Tritium source term estimates for the FHR DR design.......................................................... 13

Fig. 9. Example tritium release rate to the environment for several scenarios........................................ 14

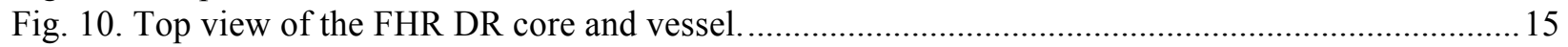

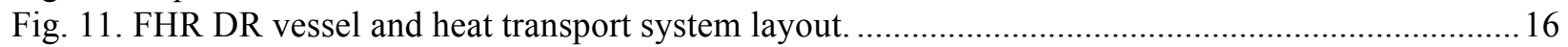

Fig. 12. Used fuel removal system (left) and the configuration used to store used fuel (right)................ 18

Fig. 13. Comparison of reactor power (top) and reactivity (bottom) calculated by TRACE and RELAP5-3D for the HFP rapid multiple rod withdrawal event.................................................2

Fig. 14. RELAP5-3D calculated coolant temperatures during a LOFF transient with SCRAM.................21

Fig. 15. Combined FHR DR notional deployment timeline (in years) and cost. ...................................24 



\section{ACRONYMS AND ABBREVIATIONS}

$\begin{array}{ll}\text { AGR } & \text { advanced gas reactor } \\ \text { AHTR } & \text { advanced high-temperature reactor } \\ \text { AOO } & \text { anticipated operational occurrence } \\ \text { ATR } & \text { advanced test reactor } \\ \text { BU } & \text { burnup } \\ \text { CAD } & \text { Canadian } \\ \text { C-C } & \text { carbon-carbon } \\ \text { CFR } & \text { Code of Federal Regulations } \\ \text { DBA } & \text { design basis accident } \\ \text { DOE } & \text { US Department of Energy } \\ \text { DR } & \text { demonstration reactor } \\ \text { DRACS } & \text { direct reactor auxiliary cooling system } \\ \text { DU } & \text { depleted uranium } \\ \text { E\&S } & \text { evaluation and screening } \\ \text { EPZ } & \text { emergency planning zone } \\ \text { FHR } & \text { fluoride salt-cooled high-temperature reactor } \\ \text { FOAK } & \text { first-of-a-kind } \\ \text { HEU } & \text { highly enriched uranium } \\ \text { HFIR } & \text { High Flux Isotope Reactor } \\ \text { HFP } & \text { hot full power } \\ \text { HTGR } & \text { high-temperature gas-cooled reactor } \\ \text { IET } & \text { integrated effects testing } \\ \text { INL } & \text { Idaho National Laboratory } \\ \text { ITER } & \text { International Thermonuclear Experimental Reactor } \\ \text { LEU } & \text { low-enriched uranium } \\ \text { LOFF } & \text { loss of forced flow } \\ \text { LWR } & \text { light water reactor } \\ \text { MHC } & \text { molybdenum-hafnium-carbide } \\ \text { MIT } & \text { Massachusetts Institute of Technology } \\ \text { MSRE } & \text { Molten Salt Reactor Experiment } \\ \text { NE } & \text { DOE Office of Nuclear Energy } \\ \text { NOAK } & \text { Nth of a kind } \\ \text { NRC } & \text { US Nuclear Regulatory Commission } \\ \text { ORNL } & \text { Oak Ridge National Laboratory } \\ \text { PB-FHR } & \text { pebble bed FHR } \\ \text { PHTS } & \text { primary heat transport system } \\ \text { PWR } & \text { pressurized water reactor } \\ \text { RD\&D } & \text { research, development, and demonstration } \\ \text { RR } & \text { replacement rate } \\ \text { SAR } & \text { safety analysis report } \\ \text { SBMS } & \text { standards based management system } \\ \text { SET } & \text { separate effects testing } \\ \text { SmAHTR } & \text { small modular AHTR } \\ \text { SMR } & \text { small modular reactor } \\ \text { SNS } & \text { Spallation Neutron Source } \\ \text { SPD } & \text { specific power density } \\ \text { TRIDENT } & \text { Tritium Diffusion Evolution and Transport } \\ \text { TRISO } & \end{array}$


TRL

TRS

UCB

USD technology readiness level

tritium release scenario

University of California, Berkeley

US dollars 


\section{ACKNOWLEDGEMENTS}

This effort was supported by the US Department of Energy Office of Nuclear Energy (DOE-NE) to evaluate advanced test and demonstration reactor concepts using a variety of technology options. We gratefully acknowledge Jess Gehin (Oak Ridge National Laboratory [ORNL]), Bob Hill (Argonne National Laboratory), David Petti (Idaho National Laboratory), and Tom O’Connor (DOE-NE).

The Fluoride Salt-Cooled High-Temperature Reactor (FHR) Demonstration Reactor (DR) effort benefits significantly from the contributions of many individuals and institutions performing research on FHRs. Credit is extended to the two integrated research projects funded by DOE-NE and led by the Massachusetts Institute of Technology (MIT) and the Georgia Institute of Technology. Charles Forsberg (MIT), Per Peterson (University of California, Berkeley), David Holcomb (Oak Ridge National Laboratory), Joshua Richard (Los Alamos National Laboratory), John Stempien (Idaho National Laboratory), Raluca Scarlat (University of Wisconsin), and Michael Laufer (University of California, Berkeley) are specifically acknowledged for their gracious sharing of information and helpful insights.

ORNL postdoctoral appointees Cole Gentry and Askin Guler contributed to this effort, and the careful review and guidance of Jess Gehin and Andrew Worrall (ORNL) are appreciated. 



\section{SUMMARY}

The fluoride salt-cooled high-temperature reactor (FHR) demonstration reactor (DR) is a concept for a saltcooled reactor with 100 megawatts of thermal output (MWt). It would use tristructural-isotropic (TRISO) particle fuel within prismatic graphite blocks. FLiBe $\left(2{ }^{7} \mathrm{LiF}_{-}-\mathrm{BeF}_{2}\right)$ is the reference primary coolant. The FHR DR is designed to be small, simple, and affordable. Development of the FHR DR is a necessary intermediate step to enable near-term commercial FHRs. Lower risk technologies are purposely included in the initial FHR DR design to ensure that the reactor can be built, licensed, and operated within an acceptable budget and schedule. These technologies include TRISO particle fuel, replaceable core structural material, the use of that same material for the primary and intermediate loops, and tube-and-shell primary-tointermediate heat exchangers. Several preconceptual and conceptual design efforts that have been conducted on FHR concepts bear a significant influence on the FHR DR design. Specific designs include the Oak Ridge National Laboratory (ORNL) advanced high-temperature reactor (AHTR) with 3400/1500 MWt/megawatts of electric output (MWe) (Holcomb et al. 2011a), as well as a $125 \mathrm{MWt}$ small modular AHTR (SmAHTR) from ORNL (Greene et al. 2010). Other important examples are the Mk1 pebble bed FHR (PB-FHR) concept from the University of California, Berkeley (UCB) (Andreades et al. 2014; Forsberg et al. 2014a), and an FHR test reactor design developed at the Massachusetts Institute of Technology (MIT) (Forsberg et al. 2014b). The MIT FHR test reactor is based on a prismatic fuel platform and is directly relevant to the present FHR DR design effort. These FHR concepts are based on reasonable assumptions for credible commercial prototypes. The FHR DR concept also directly benefits from the operating experience of the Molten Salt Reactor Experiment (MSRE), as well as the detailed design efforts for a large molten salt reactor concept and its breeder variant, the Molten Salt Breeder Reactor. The FHR DR technology is most representative of the $3400 \mathrm{MWt}$ AHTR concept, and it will demonstrate key operational features of that design. The FHR DR will be closely scaled to the SmAHTR concept in power and flows, so any technologies demonstrated will be directly applicable to a reactor concept of that size.

The FHR DR is not a commercial prototype design, but rather a DR that serves a cost and risk mitigation function for a later commercial prototype. Therefore, it would be licensed as a test or research reactor as defined by the US Nuclear Regulatory Commission (NRC), and it is expected to have a limited operational lifetime compared to a commercial plant. It is designed to be a low cost reactor compared to more mature advanced prototype DRs. A primary reason to build the FHR DR is to learn about salt reactor technologies and demonstrate solutions to remaining technical gaps. It is expected that some systems will be less mature than what is needed for commercial applications, and it is acknowledged that there will be large uncertainties when estimating the costs of some of these systems.

Simplicity in design, size, and the use of the most mature technology available enables flexibility in testing a number of concept technologies for FHRs. Because the FHR DR targets a relatively immature advanced reactor concept, a specific design is not yet available. Therefore, the point design proposed for the FHR does not target a given design concept such as SmAHTR, or AHTR. The point design will provide technology readiness level (TRL) improvements for several FHR designs in some key technology areas.

Features of the FHR DR design are shown in Fig. 1. The FHR DR core resides in a pool of primary coolant salt within a cylindrical vessel of alloy $800 \mathrm{H}$ lined with alloy N. The FHR DR vessel and piping material are capable of testing various candidate salt coolants. The vessel is housed in a reactor silo and is sealed with a removable top hatch. The space above the reactor is enclosed by a stainless steel containment barrier. The primary heat transport system (PHTS) is a two-loop system with heat transfer to independent intermediate loops each carrying $\sim 50 \mathrm{MWt}$ to a common salt containment vessel. The baseline design of the FHR DR is 
coupled to an open-air Brayton power conversion system, which is also proposed for the Mk 1 pebble bed FHR concept.

Key features of the FHR DR concept are directly relevant to and can be scaled to commercial applications. Examples include (1) the use of hexagonal fuel arrangements with TRISO fuel in a graphite matrix, (2) the ability to move and replace fuel and core structure within the vessel, and (3) active and passive direct reactor auxiliary cooling systems (DRACSs). Three isolated sections within the downcomer region on the inner vessel wall house independent heat exchangers to remove heat directly from the primary salt within the vessel in the event of a loss of flow accident and during routine maintenance outages.

The FHR DR baseline design provides for the production of electricity, but it can also demonstrate the ability of an FHR to supply low-pressure, high-temperature process heat directly to a chemical process. Heat from the intermediate salt can be shared among a number of uses, depending on the desired configuration of the plant. The estimated operating costs of the FHR DR are approximately $\$ 62 / \mathrm{MWt}-\mathrm{h}$, including cost recovery electricity sales.

With sufficiently aggressive research and development, the FHR DR can be operational within 10 years because of the use of low-risk, near-term technology options at a conservatively estimated cost of \$1.5B.
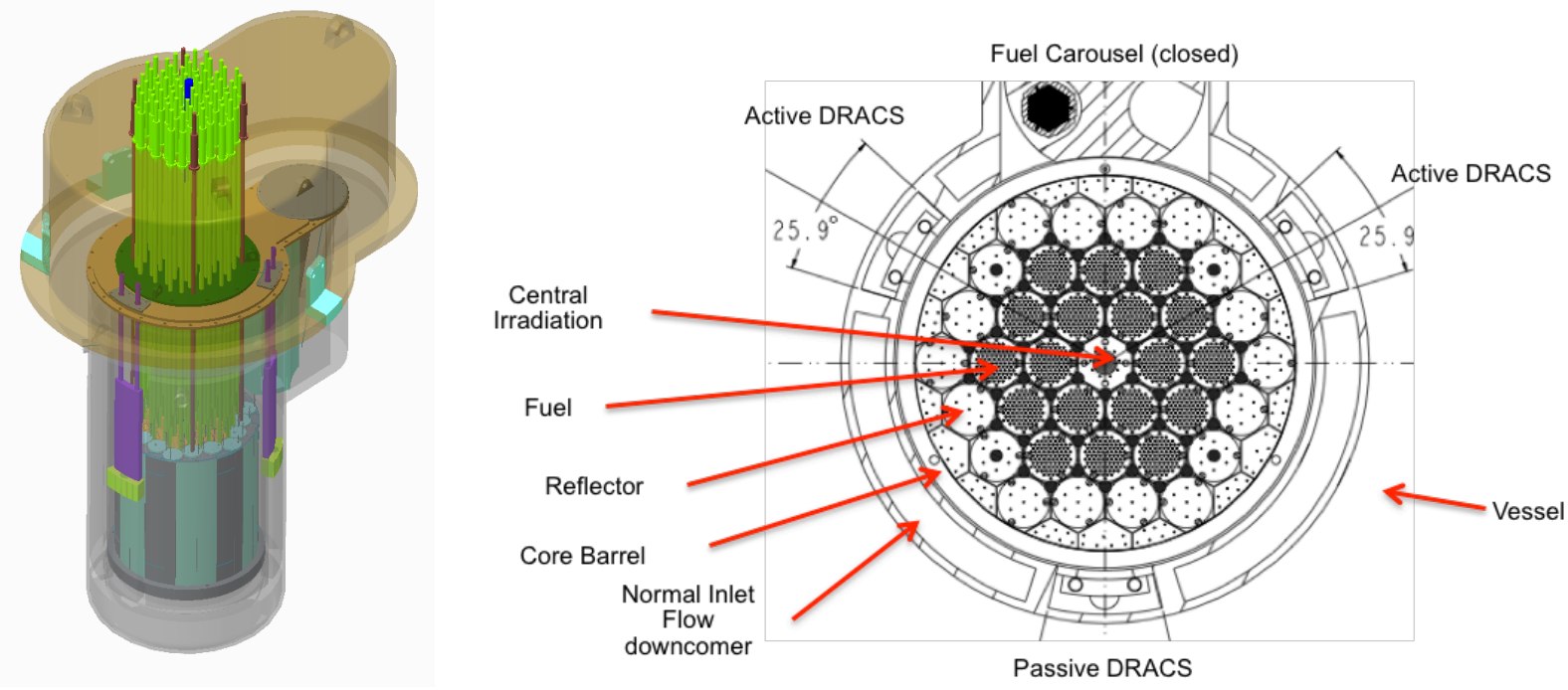

Fig. 1. FHR demonstration reactor: isometric view (left) and planar drawing (right). 


\section{OBJECTIVES AND MOTIVATION FOR CONCEPT SELECTION}

The FHR DR will significantly advance FHR technology toward the realization of a first-of-a-kind (FOAK) salt reactor commercial plant. It is a thoroughly instrumented demonstration that will provide important data for validating FHR performance and safety codes. Needed technology, including tritium management, will be developed for and demonstrated in the FHR DR.

The FHR Technology Development and Demonstration Roadmap (Holcomb et al. 2013) identified several "remaining technology challenges and the research, development, and demonstration (RD\&D) needed to address the challenges." Some key FHR technology gaps can only be addressed by successfully designing, licensing, building, and operating an FHR. These include design performance prediction, infrastructure and regulatory maturation, and development and demonstration of systems and components at capacities that can be confidently scaled to commercial deployment. Infrastructure and regulatory maturation goals include:

(1) developing and demonstrating a licensing path specifically for FHRs and by extension for advanced (non-water-cooled) reactors in general,

(2) providing validation data for computational modeling and simulation capabilities in areas including reactor analysis, safety performance and salt chemistry modeling,

(3) demonstrating key fabrication techniques for FHR reactor components, and

(4) developing a supply chain for FHR-specific components and materials, including fuels and salts.

System and component technology goals include:

(1) developing and demonstrating FHR-specific instrumentation and control systems,

(2) fuel performance demonstration and qualification, and

(3) using refueling technologies needed to support commercial FHR operation.

Each of these technology needs can and will be developed to some maturity level outside of the FHR DR using separate effects testing (SET) facilities and integrated effects testing (IET) capability, but an operating FHR DR will enable focused and rapid technological maturation, prototypic deployment, and credible demonstration. Thus, the FHR DR is the keystone of a broader set of FHR technology development and demonstration efforts and fulfills a crucial role in FHR technology development by advancing the technological maturity and readiness level of salt systems as a whole.

The FHR DR 100 MWt thermal power level represents the power of DOE's operating reactors, the High Flux Isotope Reactor (HFIR) at ORNL (85 MWt) and the Advanced Test Reactor (ATR) at Idaho National Laboratory (INL) (250 MWt), and it is similar to the power level of the SmAHTR design (125 MWt). This power level is sufficient for fuel irradiation and produces operational characteristics relevant to large FHR commercial systems. It also represents power levels being considered for several small modular reactor concepts. The material combinations in the FHR DR's primary system are those currently considered to be most suitable for a near-term demonstration. They were chosen based on increased maturity, availability, and licensing considerations. The choice to use available materials will allow the FHR DR to be operational sooner to test commercially attractive materials in a relevant environment in the shortest time possible. The mixed mean reactor coolant outlet temperature is slightly above $700^{\circ} \mathrm{C}$. Fig. 2 shows elevation views of the reactor with dimensions. 


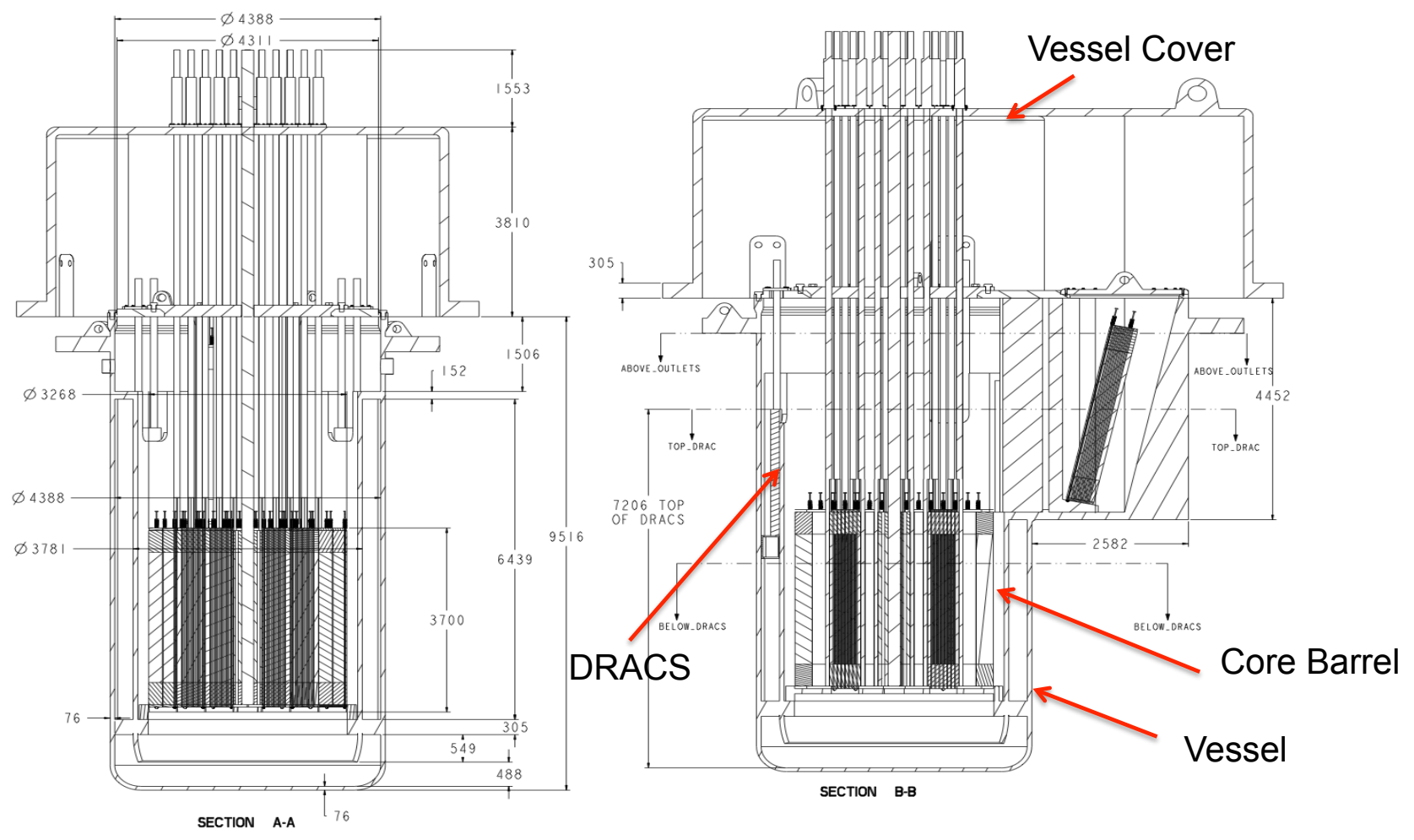

Fig. 2. Elevation view of the FHR DR showing the reactor core within the vessel.

\section{POINT DESIGN DESCRIPTION}

\subsection{REACTOR FUEL FORM AND CONFIGURATION}

The FHR DR uses prismatic block-type fuel with integral fuel compacts and coolant channels as its base fuel form. The fuel is a typical next generation nuclear plant particle geometry with $15.5 \% \mathrm{UC}_{0.5} \mathrm{O}_{1.5}$ TRISO kernels with packing fractions of 0.35 within compacts. Selection of prismatic block-type fuel was motivated by the manufacturability of the prismatic fuel for high-temperature gas-cooled reactors (HTGRs), and all design parameters, including the particle packing fraction, are based on current experience. TRISO fuel acts as a miniature pressure vessel containing fission products and is the first of several layers of defense against fission product release. The recent successful experience in the advanced gas reactor (AGR) fuel irradiation program is another reason for this selection. Prismatic block fuel provides significant flexibility in enrichment zoning, fuel-coolant-moderator ratio, coolant distribution, and other core design parameters. The single batch cycle length of the FHR DR core is estimated at 18 months assuming the successful qualification of structural composite tie rod material. Both single and multi-batch fuel management are expected to be demonstrated in the FHR DR. However, the initial fuel management approach is expected to be single batch. The core consists of 18 fueled hexagonal positions surrounded by 18 full-sized unfueled reflector positions, as shown in Fig 3. A full-sized central hexagonal position is reserved for irradiation and instrumentation services. Partial sections fill in the outer edges to complete the circle, which limits bypass flow between the core and the core barrel that forms the downcomer region within the vessel. The fueled height of the core is approximately $2.61 \mathrm{~m}$, and unfueled sections extend approximately $44 \mathrm{~cm}$ above and below. The core measures $3.24 \mathrm{~m}$ across and $3.60 \mathrm{~m}$ high.

The FHR DR will use low-enriched uranium (LEU) fuel particles identical to those being qualified under the AGR Program. The AGR Program will address the fuel performance parameters relevant for both the FHR 
DR and the commercial concepts. The fuel form is compacted within prismatic graphite blocks for which there is significant experience in gas-cooled reactors. The FHR DR will also have the ability to demonstrate and qualify alternative fuel forms. An example alternative fuel form is plank fuel, the fuel form for the SmAHTR and AHTR systems. The FHR DR core is within the same form factor as the SmAHTR core but with a reduced height. The control rods in the FHR DR are prototypes of those in SmAHTR and AHTR. Therefore, an eventual plank fueled FHR DR core configuration is possible if the plank fuel form is qualified and considered promising for commercial deployment. Directly cooled fuel compacts are another example fuel form proposed in early iterations of the SmAHTR design. Other potential fuel forms, such as pebblebased fuel, could be qualified in the FHR DR using a fixed bed of pebbles. Example alternative configurations of the FHR DR based on plank and directly cooled fuel compacts are shown in Fig. 3.

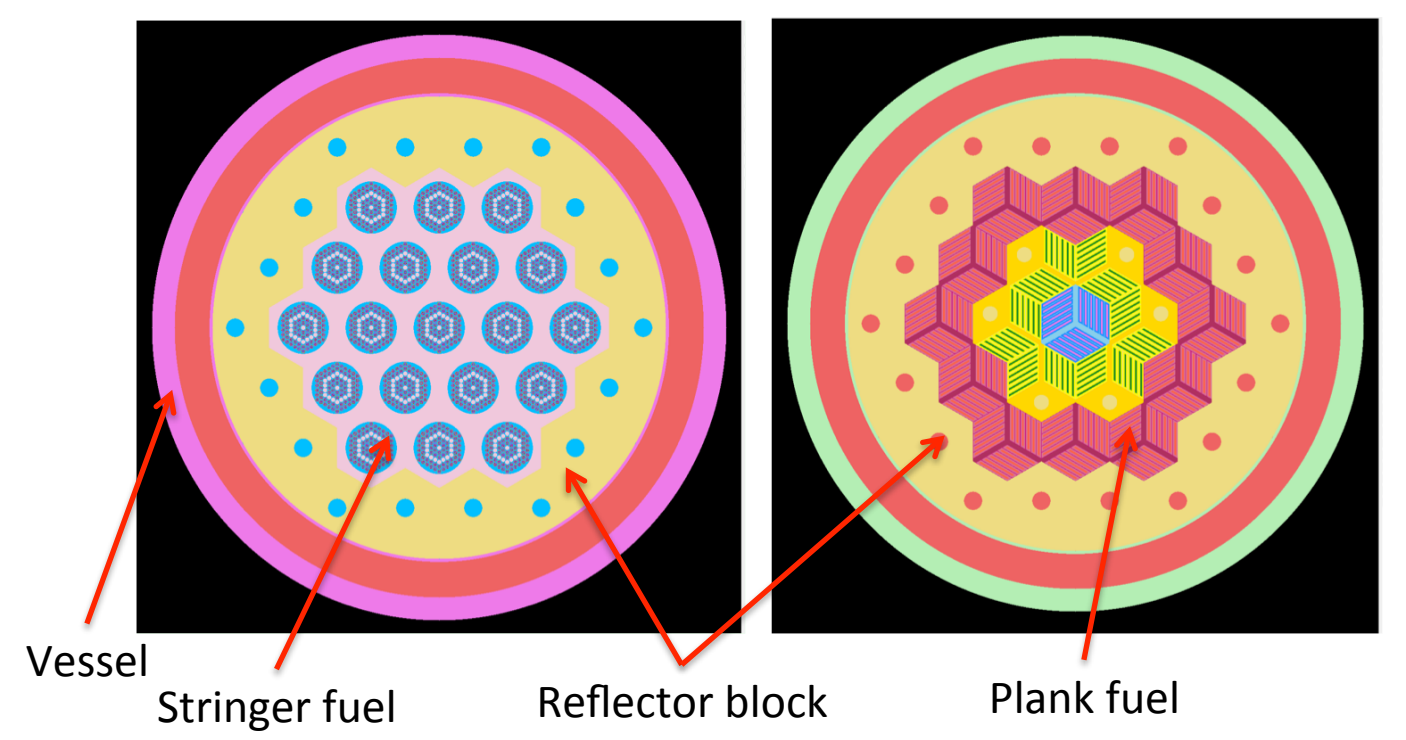

Fig. 3. Notional alternative fuel types in the FHR DR form factor: directly cooled compacts (left) and plank fuel (right) (Ilas et al. 2010).

A scoping comparison of several key TRISO fuel fabrication and performance indicators shows that the FHR DR is expected to be included in irradiation testing performed for AGR fuel qualification. Fig. 4 was generated using values for these parameters from the most relevant documents (Andreades et al. 2014, Collin 2015, Petti 2006, Varma 2012). In some cases, estimates were used where precise data were not available. Fig. 4 and Fig. 5 provide a general picture of how the FHR DR point design fits into the parameter space. The Fig. 4 parameters are based on the maximum local values (temperature, burnup, fast fluence) expected in a multibatch fuel cycle. The expected TRISO fuel performance indicators of the FHR DR are directly relevant to and/or include the key fuel performance parameters of a commercial AHTR. If it is necessary to qualify future AHTR fuels forms (e.g., plank fuel with TRISO particles) in an FHR-relevant environment, the expected fast fluence of the AHTR can be achieved by using the irradiation thimbles of the FHR DR over multiple cycles. Powers (2011) discusses the relevance of the programs shown in Fig. 5. The majority of the highly enriched uranium (HEU) data points in Fig. 5 were from experiments in which fissile fuel was being used to drive fertile thorium fuel (Powers 2011). 


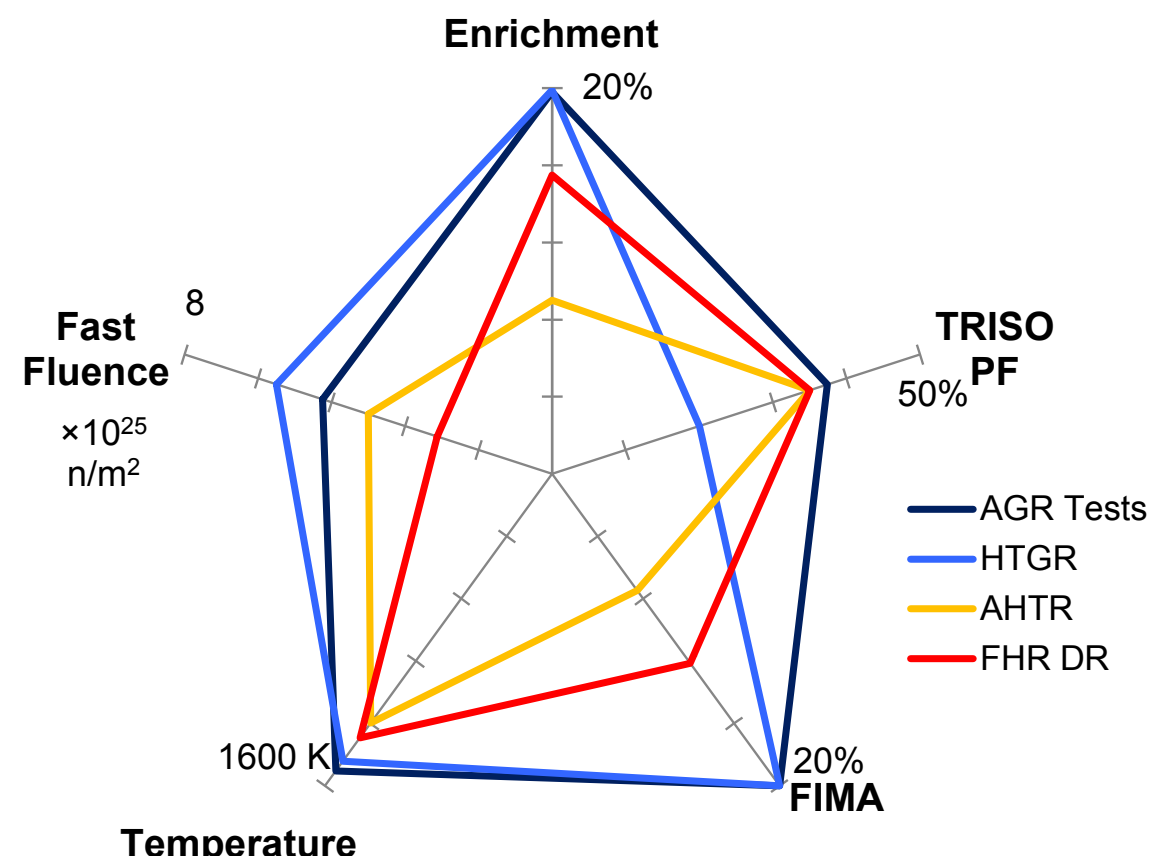

Fig. 4. FHR DR estimated fuel fabrication and performance indicators.
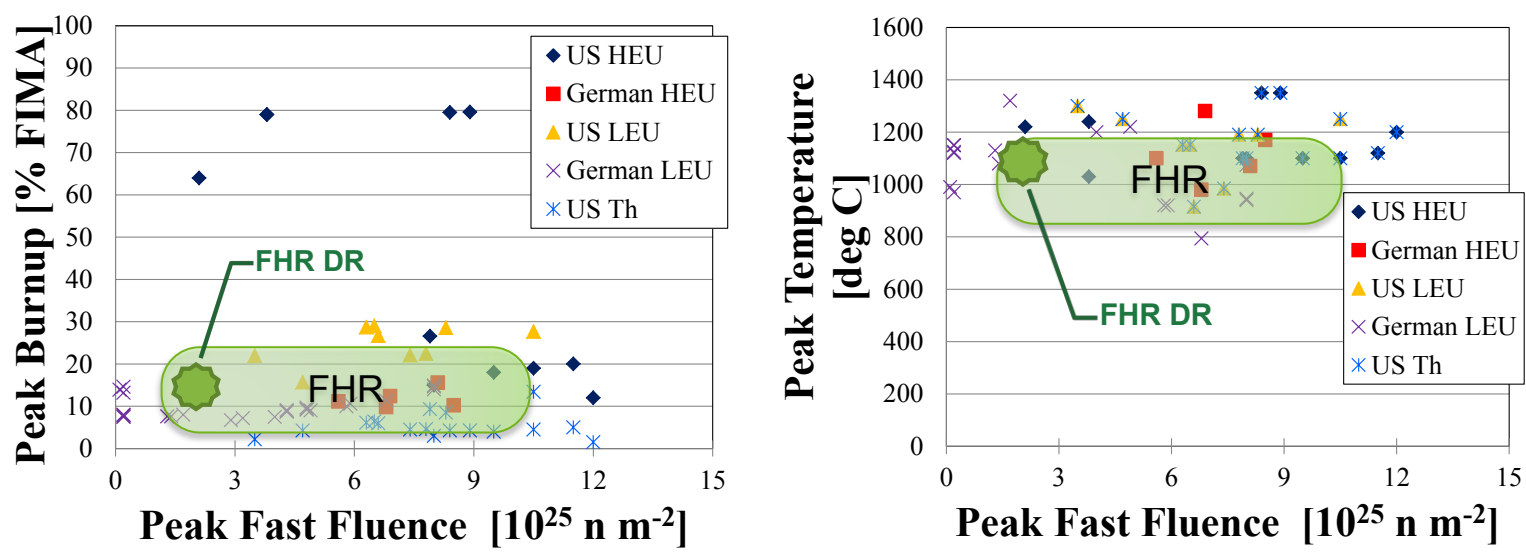

Fig. 5. Peak burnup, temperature, and fast fluence.

Based on the indicators shown in this report, the FHR DR will demonstrate fuel performance that is both prototypic and at scale for commercial FHRs of interest such as SmAHTR and/or an AHTR. The fuel fabrication processes involved would also be prototypic and at scale for commercial FHRs using prismatic fuel forms, which have been investigated during past AHTR studies. The scale of the FHR DR is more relevant to the SmAHTR concept, which is the primary commercial target. However, features relevant to other concepts such as the AHTR and the PB-FHR will also be demonstrated in the FHR DR. The proposed FHR DR concept would be designed to contain sufficient instrumentation to support licensing needs for all commercial FHRs. Validation data from the FHR DR fuel to support licensing would include fission gas release data, spatial distributions of fission product concentrations in fuel, and/or core components to examine the rate and extent of fission product diffusion, temperatures, and possibly post-irradiation determination of fuel kernel migration and coating layer thicknesses. The data needed will also include 
fission product concentrations in the salts and surrounding atmospheres. In addition, post-irradiation examination of fuel will provide significant information, including indication of fuel failure rates through fission gas measurements, temperature-dependent fission product retention from fuel particles and compacts, and irradiated material properties of the fuel and matrix materials used. Isolating samples of irradiated fuel particles using focused ion beams or other techniques could enable detection of kernel migration issues or statistical analysis of post-irradiation interfacial surface bonds and coating thicknesses. All of this data would underpin the fuel technology and would validate computation models. Parameters such as stress in the fuel particle coating layers would not be directly validated due to the inherent difficulty in measuring such a parameter; however, other out-of-pile tests could prove useful for this purpose, such as performing crush tests with unirradiated samples to validate yield stresses for coating layers and integral particles.

Fully ceramic microencapsulated fuel with a $\mathrm{SiC}$ matrix and uranium-nitride based TRISO fuel is another possible FHR fuel form (Terrani et al. 2012, Powers 2014). Fuel forms based on high-density, high-thermal conductivity ceramic materials (such as $\mathrm{UN}-\mathrm{U}_{3} \mathrm{Si}_{5}$ or $\mathrm{U}_{3} \mathrm{Si}_{2}$ ) with advanced cladding ( $\mathrm{SiC}-\mathrm{SiC}$ or molybdenum-based systems) could eventually be tested in the FHR DR. These advanced fuel forms are under development by the DOE Office of Nuclear Energy (NE) Advanced Fuel Campaign (Brown et al. 2014, George et al. 2014, Brown et al. 2015, White et al. 2015) for use in light water reactors (LWRs). The advanced fuel forms may offer advantages for the fuel cycle, and preliminary reactor physics analysis suggests they might be feasible in the FHR DR design.

The FHR DR uses molybdenum-hafnium-carbide (MHC) control rods positioned at the intersections of hexagonal blocks. Commercially available MHC features high density, strength, and corrosion resistance, which are the primary factors for its selection as the baseline reactivity control material. Control rods are inserted into the core using mechanisms mounted to a removable central top plug on the vessel's top hatch. The rods are detachable from the control drive mechanisms and sink in the primary coolant to remain in the core when detached. Access to perimeter instrumentation and irradiation locations is through openings on the outer ring of the vessel's top hatch. The instrumentation equipment is contained in cylindrical primary boundary containment housings that extend from the top hatch to the bottom of the reactor core. They can be removed and stored to facilitate core shuffling and refueling. The control rod and instrumentation positions are shown in Fig. 6. The numbers and locations of the instrumentation and irradiation positions are selectable and reconfigurable. 

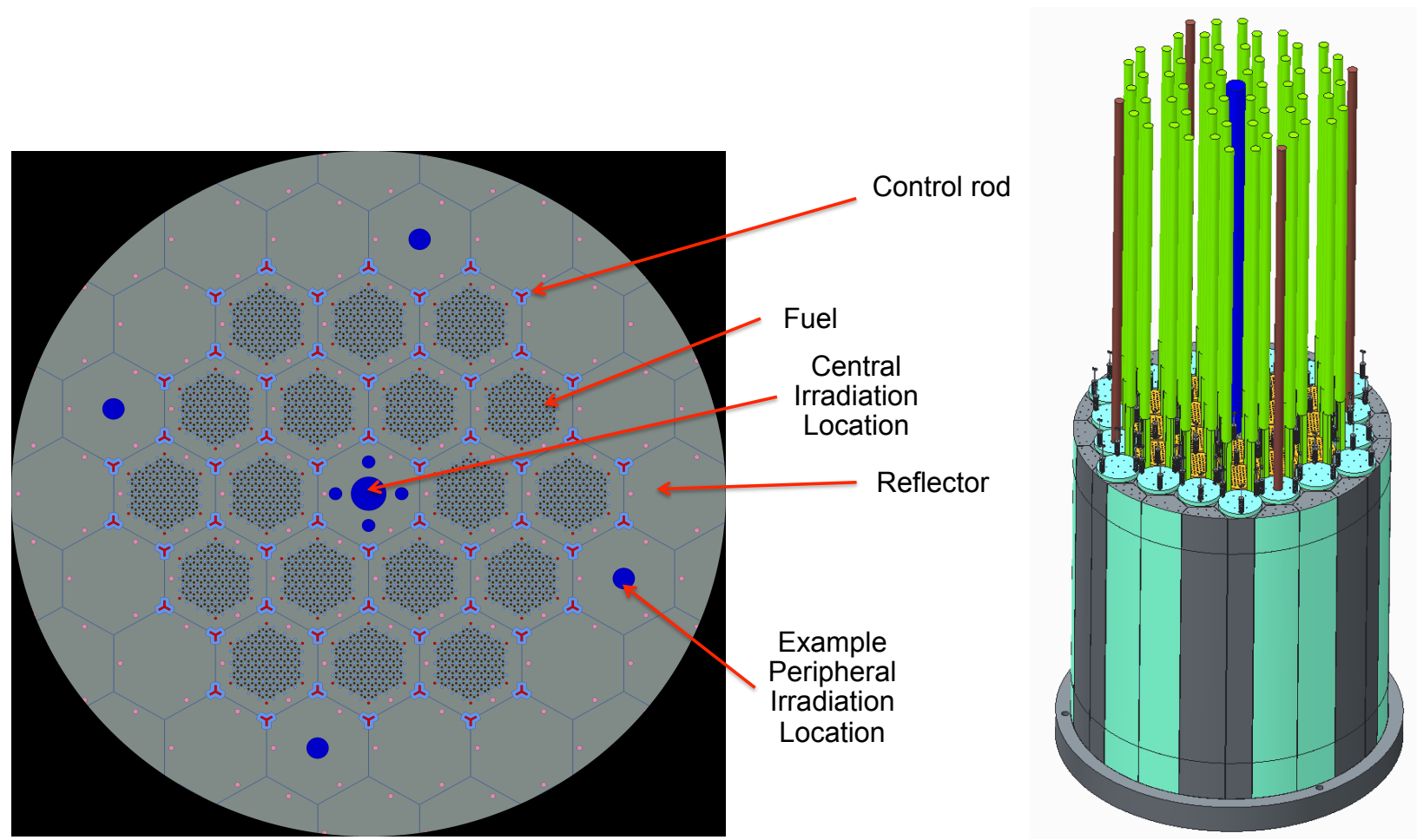

Fig. 6. Radial core layout of the neutronic model (left) and isometric view showing core components (right).

A series of stacked blocks - an upper unfueled section, fueled central sections, and a lower unfueled section - are structurally connected using tie rods to form an integrated hexagonal fuel element spanning the height of the core. Each block assembly rests on a lower core support plate attached to an internal support flange within the vessel. Fuel block assemblies are outfitted with lifting and positioning hardware to allow for placement into the lower core support plate and for positioning and stabilization within the core. The spent fuel handling system of the FHR DR is prototypic and scalable to the AHTR and is similar to several other advanced reactor concepts (Waltar et al. 2012).

An orifice plate adds weight to the bottom of each block assembly to ensure that the assembly sinks in the primary coolant. The plates intersect with the lower core support structure in a self-aligning manner, and connecting tie rods extend to the top to allow the blocks to be held together. Rotatable, spring-loaded cleats at the top of each fuel assembly form an interlocking upper core structure which engages and locks adjacent block assemblies into position. Fuel block assemblies are also constrained by an upper hold-down plate as a redundant measure to prevent detached fuel elements from lifting away from the lower support structure. The lower plates of each block move independently within the lower support structure to accommodate unique thermal expansion and/or dimensional changes experienced by individual blocks within the core.

To control excess reactivity at the beginning of a cycle, each fueled assembly includes six burnable absorber rods located on the corners of the fuel region. These rods also reduce temperatures along the edges of the fueled regions where the ratio of cooling channels to fuel channels is reduced. Absorber rods are composed of graphite with small weight fractions $(<2 \%)$ of natural $\mathrm{B}_{4} \mathrm{C}$ as a neutron absorber material similar to those used in HTGRs.

\subsection{REACTOR CORE CONFIGURATION}

The reference fuel cycle for the FHR DR is a once-through fuel cycle with LEU fuel (enrichment of 15.5\%), but the FHR DR is also capable of multibatch operation. The FHR DR is a thermal spectrum reactor, and the 
natural uranium resource utilization is less than $1 \%$ assuming a once-through cycle. The reference fuel form is UCO kernel TRISO particles. In the context of the DOE-NE nuclear fuel cycle evaluation and screening (E\&S) (Wigeland et al. 2014), the relevant evaluation group is EG02. The analysis example for EG02 was a graphite-moderated, He-cooled, TRISO-fueled high-temperature reactor.

Table 1 shows fuel cycle performance parameters relevant for single-batch and three-batch fuel management schemes, with several different fuel packing fractions and example tie-rod materials. Assuming that carbon or silicon carbide structural materials are demonstrated, the fuel cycle performance of the FHR DR is drastically improved. The best performance of the FHR DR in terms of natural resource utilization is 213 metric tons of natural uranium per gigawatt electric year (t/GWe-yr). The best natural resource utilization for a single-batch fuel cycle is $320 \mathrm{t} / \mathrm{GWe-yr}$, corresponding to a 549-day single batch cycle length with a $90 \%$ capacity factor. This assumes qualification of an acceptable ceramic composite tie rod material. The base case with a nickel-based tie rod material features a natural resource utilization for a single-batch fuel cycle of $376 t / G W e-y r$, corresponding to a 312-day single batch cycle length with a $90 \%$ capacity factor. The assumed electricity generation efficiency is $42 \%$, although it is possible that the FHR DR would be capable of generating electricity at higher thermal efficiencies because of its high outlet temperature.

Table 1. Example fuel cycle performance parameters of the FHR DR

\begin{tabular}{lccccc}
\hline Parameter & \multicolumn{5}{c}{ Value } \\
\hline Enrichment (\%) & & \multicolumn{3}{c}{0.9} \\
Capacity factor & & & 0.42 & \\
Electrical efficiency & & & & \\
Packing fraction & - & 0.35 & 0.35 & 0.3 & 0.25 \\
Tie rod material & & Alloy & C-C or & C-C or & C-C or \\
& & $800 \mathrm{H}$ & SiC-SiC & SiC-SiC & SiC-SiC \\
Burnable poison? & Yes & No & No & No \\
Burnup (GWd/t) & 1-batch & 51.1 & 90 & 76.6 & 56.8 \\
& 3-batch & 76.6 & 135 & 115 & 85.2 \\
Fuel residence time (full power & 1-batch & 312 & 549 & 405 & 246 \\
days) & 3-batch & 468 & 823 & 608 & 370 \\
Charge mass flow (t/GWe-yr) & 1-batch & 17 & 9.7 & 11.3 & 15.3 \\
& 3-batch & 11.4 & 6.4 & 7.6 & 10.2 \\
Natural resource required & 1-batch & 563 & 320 & 375 & 507 \\
(t/GWe-yr) & 3-batch & 376 & 213 & 250 & 338 \\
\hline
\end{tabular}

The fuel cycle performance parameters in Table 1 were calculated using the methodology from the E\&S (Wigeland et al. 2014):

- Fuel residence time:

$F R T(y r)=\frac{B U(M W d / t)}{S P D(M W / t) \times 365(d / y r) \times \eta}$,

- Cycle length:

$$
C(y r)=\frac{F R T(y r)}{n_{\text {batch }}},
$$

where

$$
\begin{aligned}
& \mathrm{P}_{\text {thermal }}=\text { reactor thermal power }[\mathrm{MW}], \\
& \mathrm{SPD}=\text { specific power density }[\mathrm{MW} / \mathrm{t}],
\end{aligned}
$$




$$
\begin{aligned}
& \mathrm{n}_{\text {batch }}=\text { number of fuel batches in the core, } \\
& \mathrm{BU}=\text { fuel average discharge burnup }[\mathrm{MWd} / \mathrm{t}] \text {, } \\
& \eta \quad=\text { reactor capacity factor, and } \\
& e n r=15.5 \% \text { for LEU, } 0.25 \% \text { for tails, and } 0.711 \% \text { for natural uranium (NU). }
\end{aligned}
$$

The fraction of the electricity generated is $100 \%$ for this one-stage fuel cycle. The charge fuel mass and natural resources required per unit electricity generation were obtained from

$$
\begin{aligned}
& \text { - Charge fuel mass: } \quad \bar{M}_{\text {charge }}^{\text {fuel }}\left(\frac{t}{G W e \cdot y r}\right)=\frac{P_{t h}(M W)}{B U(G W d / t) P_{e l}(M W)} \cdot \frac{365.25 d}{1 y r} \text {, and } \\
& \overline{M_{N U}}=\overline{M_{\text {charge }}^{\text {fuel }}} \times\left(e n r_{L E U}-e n r_{\text {tails }}\right) \div\left(e n r_{N U}-e n r_{\text {tails }}\right) .
\end{aligned}
$$

The FHR DR could also demonstrate a portion of an advanced fuel cycle. One option is the use of uranium and thorium feed fuel in TRISO form (UTh feed). This would use both LEU fuel and fertile thorium fuel, corresponding to EG05 in the E\&S (Wigeland et al. 2014). Another potential example of an advanced fuel cycle application of the FHR DR is the use of deep-burn TRISO fuel with plutonium or transuranic recycle. Thus, the proposed fuel materials (in TRISO particle form) that could be demonstrated in the FHR DR include LEU fuel, UTh fuel, plutonium fuel, and transuranic fuel.

The graphite-moderated baseline configuration of the FHR DR is designed to provide peak thermal fluxes in the central irradiation thimble. This thimble will be used to qualify desired fuel forms in commercially relevant FHR irradiation conditions and will be instrumented to enable validation of high-fidelity simulation tools. The radial thermal and fast flux distributions in the FHR DR are shown in Fig. 7. The peak thermal flux (less than $0.625 \mathrm{eV}$ ) in the central irradiation thimble is $2.5 \times 10^{14} \mathrm{n} / \mathrm{cm}^{2}$-s, and the peak fast flux (greater than $0.1 \mathrm{MeV}$ ) attainable is $1.25 \times 10^{14} \mathrm{n} / \mathrm{cm}^{2}$-s. 


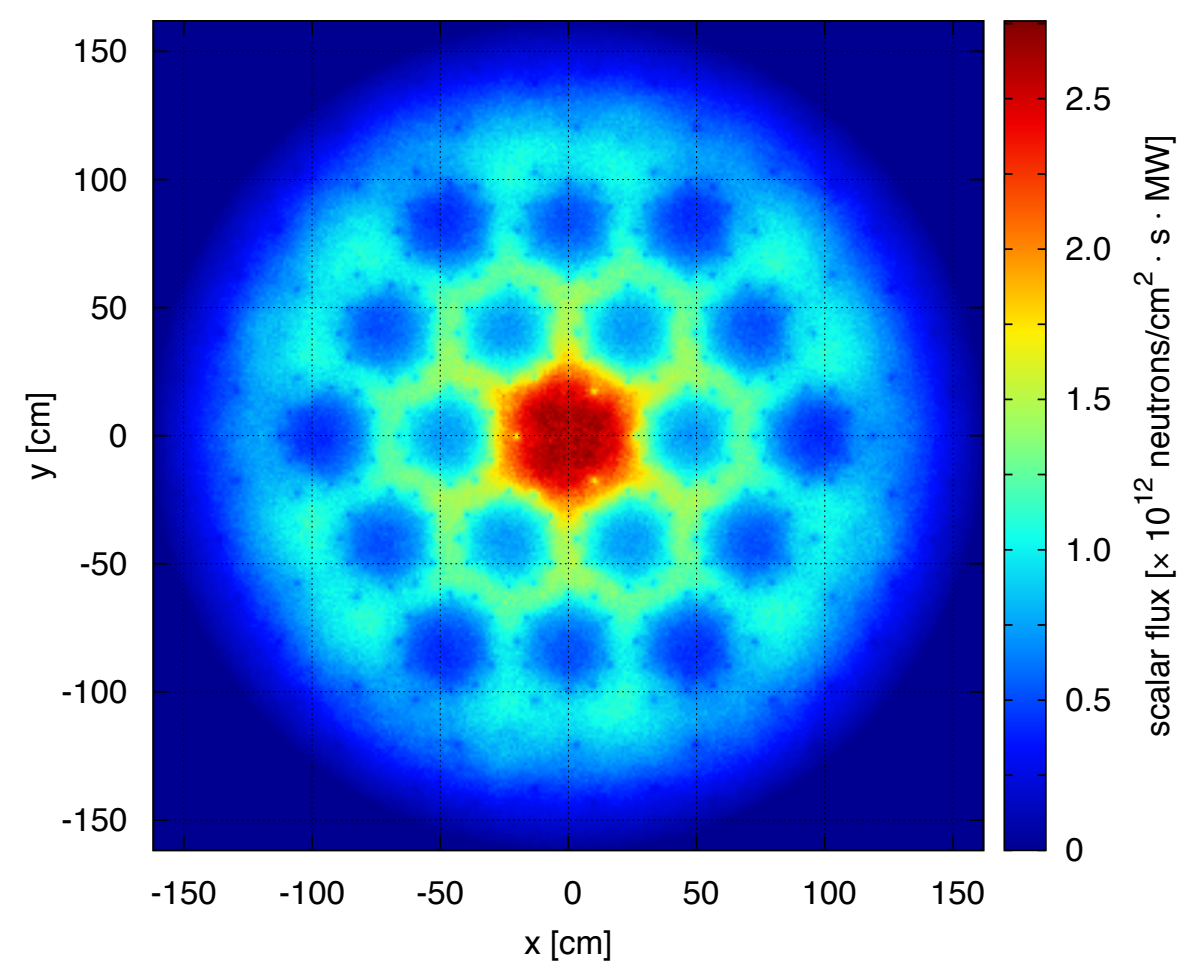

Fig. 7. FHR DR radial thermal flux distribution.

The FHR DR core is designed to be reconfigurable, with more than three possible permutations. The base configuration consists of two rings of fuel assemblies with a central irradiation zone. There are nine irradiation thimbles spanning the axial height of the core, which is $3.5 \mathrm{~m}$. The thimbles include four irradiation thimbles on the periphery of the core, four small irradiation thimbles in the central thimble, and the large central test position. In another core configuration, such as a configuration where the central test thimble is replaced with a fuel block, the irradiation volume available would be different. The reflector blocks can also be replaced with blocks containing irradiation thimbles. The available irradiation volumes in the FHR DR base configuration are detailed in Table 2. These volumes and thimble configurations are preliminary, and they assume that $40 \%$ of the thimble radii is available for irradiation volume. The total available irradiation volume is $30 \mathrm{~L}$, and $3 \mathrm{~m}$ of axial height is available for irradiation.

Table 2. Irradiation volumes in the FHR DR baseline configuration

\begin{tabular}{lccc}
\hline Irradiation volume & $\begin{array}{c}\text { Number of } \\
\text { locations }\end{array}$ & $\begin{array}{c}\text { Available axial } \\
\text { height (m) }\end{array}$ & $\begin{array}{c}\text { Available } \\
\text { volume (L) }\end{array}$ \\
\hline Large central thimble & 1 & 3 & 10 \\
Small central thimbles & 4 & 3 & 5 \\
Peripheral thimbles & 4 & 3 & 15 \\
\hline
\end{tabular}

The current configuration is not a final design, but it is an acceptable baseline core arrangement for further FHR DR study and development. Many core arrangements are possible, and flexibility in core configuration is a key feature of the concept. The current configuration is a single-batch fuel management scheme with an operating cycle of 18 months. An allowed 50-day outage for refueling and maintenance results in an expected availability of greater than $90 \%$. 
The current core configuration assumes nickel-plated alloy $800 \mathrm{H}$ tie rods for fuel element structural materials. Alloy $800 \mathrm{H}$ is a near-term option with excellent high-temperature strength, but it has relatively high parasitic neutron absorption due to nickel and iron content. If carbon-carbon (C-C) composites or SiC structural tie rods are possible, significantly longer single-batch cycle lengths are achievable. The peak fast neutron fluence $(>0.18 \mathrm{MeV})$ expected in the TRISO fuel kernels is $3.5 \times 10^{21} \mathrm{n} / \mathrm{cm}^{2}$. The maximum thermal flux achievable in the central thimble is $2.5 \times 10^{14} \mathrm{n} / \mathrm{cm}^{2}-s$, although this varies with fuel packing fraction and enrichment, core loading, and fuel assembly tie rod material. Key reactor design parameters of the current FHR DR configuration are shown in Table 3.

Table 3. Key reactor parameters

\begin{tabular}{|c|c|c|}
\hline Parameter & Unit & Value \\
\hline Reactor thermal power & $\mathrm{MWt}$ & 100 \\
\hline $\begin{array}{l}\text { Targeted net thermal efficiency of derived } \\
\text { commercial application }\end{array}$ & $\%$ & 42 \\
\hline Primary coolant & & $2^{7} \mathrm{LiF}-\mathrm{BeF}_{2}$ \\
\hline Lithium-7 enrichment level & $\%$ & 99.995 \\
\hline Fuel type & & $\mathrm{UC}_{0.5} \mathrm{O}_{1.5}$ coated particle \\
\hline Fuel packing & $\%$ & $30-40$ \\
\hline${ }^{235} \mathrm{U}$ enrichment level & $\%$ & 15.5 (baseline) \\
\hline Reflector material & & Graphite \\
\hline Reactor vessel internals material & & Alloy $800 \mathrm{H}$ lined w/alloy $\mathrm{N}$ \\
\hline Core structural material & & $\mathrm{C}-\mathrm{C}$ composites \\
\hline Control blade material & & MHC alloy \\
\hline Primary coolant flow rate & $\mathrm{kg} / \mathrm{s}$ & $\sim 1000$ \\
\hline Number of primary loops & & 2 \\
\hline Refueling interval & Months & $\sim 12(3$ batch $)-18(1$ batch $)$ \\
\hline Fuel format & & $\begin{array}{l}\text { Prismatic block with coolant channels } \\
\text { and fuel compacts }\end{array}$ \\
\hline Mixed mean core outlet temperature & ${ }^{\circ} \mathrm{C}$ & 701 \\
\hline Core inlet temperature & ${ }^{\circ} \mathrm{C}$ & 660 \\
\hline Number of fuel assemblies & & $\begin{array}{l}18 \text { fueled (baseline core, configuration } \\
\text { is flexible) }\end{array}$ \\
\hline Core fueled height & $\mathrm{m}$ & 2.61 \\
\hline Core pressure drop for normal operation & atm & 0.6 \\
\hline
\end{tabular}

\subsection{PRIMARY SYSTEM SALT COOLANT AND TRITIUM MANAGEMENT}

FLiBe features relatively attractive coolant properties and is also a neutron moderator. This combination results in coolant temperature and void coefficients that are either negative or negligible, which makes it the coolant of choice for many commercial FHR concepts. A challenge with FLiBe coolant is the production of tritium $\left({ }^{3} \mathrm{H}\right)$, a radioactive isotope of hydrogen. An economically attractive and technically viable tritium management solution is necessary for the commercial FHR deployment, and a vital role of the FHR DR is to enable in situ technology readiness level advancement of tritium management technologies. Tritium is produced largely due to radioactive transmutation of ${ }^{6} \mathrm{Li}$, which is produced by the $\mathrm{Li}$ in the salt and can also be produced through beryllium transmutation. The tritium production rate is highest when the concentration of ${ }^{6} \mathrm{Li}$ is highest and initial and equilibrium tritium production rates in an FHR are therefore different. Whether the higher rates occur at equilibrium or during initial operation depends on the initial enrichment of ${ }^{7} \mathrm{Li}$, and the time to equilibrium depends on initial salt properties, reactor flux levels, and overall primary salt inventories. The estimated tritium source term (in curies per gigawatt thermal per day) from the FHR DR 
assuming an initial enrichment of ${ }^{7} \mathrm{Li}$ of $99.995 \%$ is shown in Fig. 8 as a function of possible FLiBe inventories in the primary system.

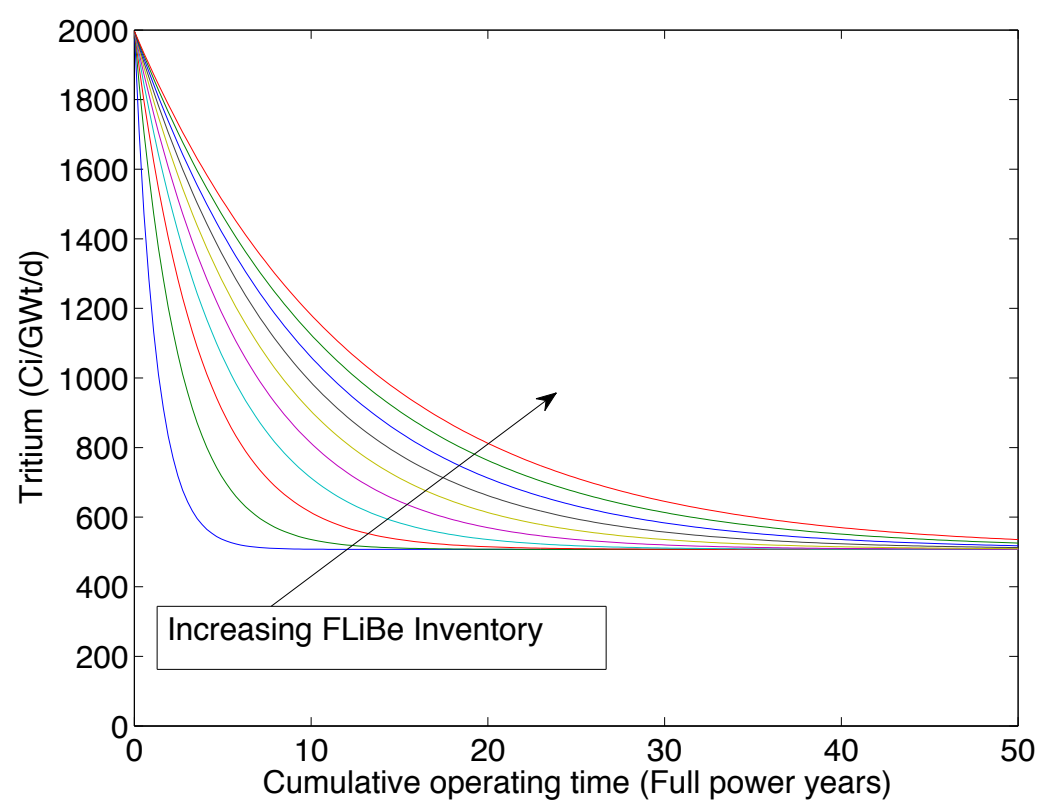

Fig. 8. Tritium source term estimates for the FHR DR design.

To develop bounding estimates on tritium transport, the Tritium Diffusion Evolution and Transport (TRIDENT) model was adapted to reflect the characteristics of the FHR DR (Stempien et al. 2015). A few key parameters of the model adapted include the neutron flux of the reactor, the volume of FLiBe exposed to the core neutron flux (determines formation rate of tritium), the volumes and surface areas of graphite (for adsorption and corrosion considerations), and the piping (e.g., heat exchanger) surface area. The FHR DR TRIDENT model was used to investigate the release rate of tritium to the environment and the potential impacts of a tritium capture system on the release rate. Figure 9 demonstrates the resulting release rates for three example mitigation scenarios. The base case tritium release scenario (TRS) assumes no tritium management, and the other two scenarios assume tritium capture devices (graphite bed) with a 1\% or 10\% replacement rate (RR) per day. All cases assume an 18-month cycle, any tritium that diffuses through the piping is released to the environment (i.e., no secondary sweep gases), only the primary loop is considered (i.e., diffusion into a secondary system is assumed to have escaped to the environment), and the assumed initial lithium purity is $99.995 \%{ }^{7} \mathrm{Li}$. With respect to the base scenario, with no tritium capture mechanisms considered, the data demonstrate that a tritium capture mechanism is necessary to keep tritium release rates below current regulatory requirements. However, the results from the TRS with $10 \%$ RR of the graphite bed indicate that recovery systems with modest online replacement (e.g., the tritium capture material can be removed and replaced with fresh unsaturated material) should be capable of reducing tritium release to levels at or below existing commercial LWRs. For example, the release rate to the reactor coolant system at Watts Bar Unit 1 is approximately $1 \mathrm{Ci} /$ day of direct/soluble tritium (Tennessee Valley Authority 2015). Another estimate of release to the environment for a large LWR with zirconium-based cladding is on the order of 2 Ci/day (Strasser et al. 1982). 


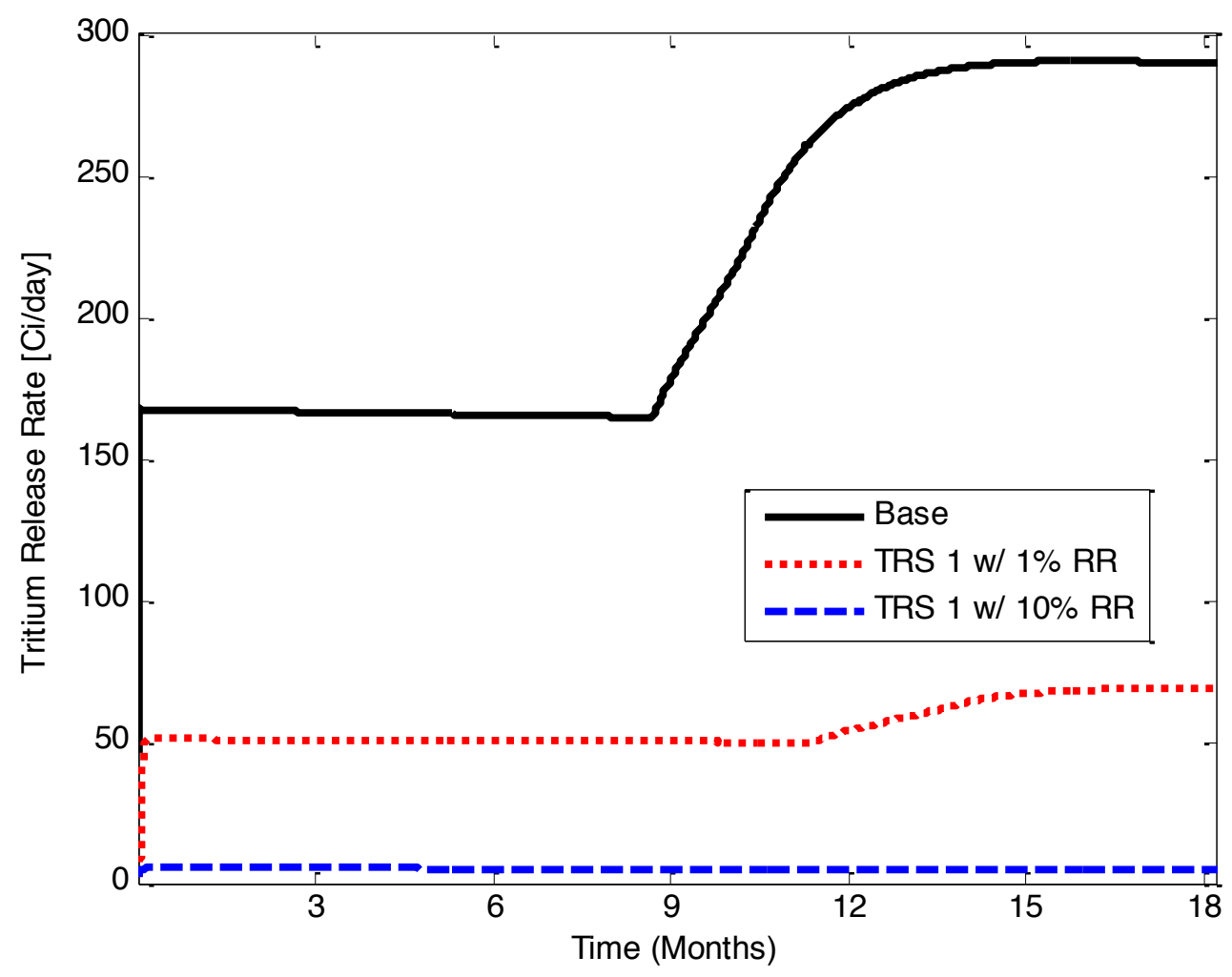

Fig. 9. Example tritium release rate to the environment for several scenarios.

The use of replaceable gettering materials for tritium management is derived from MIT, its partners at UCB, and the University of Wisconsin-Madison. The original approach was to getter tritium using a packed bed of spheres within the primary system outside the reactor core within the hot legs of the PHTS. A fraction of the spheres is periodically removed and heated to drive off the gettered tritium. The preliminary scoping evaluation of this methodology concluded that, for the FHR DR, the required volume of the gettering material would be large if it were spherical graphite. To improve this concept, a graphite form with high tritium gettering capability, large surface area per unit volume, and low flow resistance would be required. Also, methods must be developed to remove this material from the primary salt and regenerate it or replace it with fresh material during operation.

The International Thermonuclear Experimental Reactor (ITER) will be an experimental magnetic confinement fusion device and will use tritium in substantial quantities as one of its plasma fuel constituents. Thus the facility is designed to handle large quantities of elemental tritium as part of routine fueling cycle operations. ITER systems that handle tritium are designed so that all components exposed to tritium have a secondary containment barrier beyond the primary containment volume. The ITER buildings that house tritium components use detritiation systems to capture any leaks that occur into the building atmosphere. Over its lifetime, the FHR DR will produce a modest amount of tritium compared to that used in one day in ITER. Component design, building monitoring and detritiation systems, and equipment replacement protocols for FHR will follow those developed for ITER.

\subsection{REACTOR VESSEL}

A top view of the FHR DR vessel and core is shown in Fig. 10. It shows the top of the reactor core and the locations of control rods and instrumentation ports, the core barrel defining the downcomer region, and the 
DRACS heat exchangers in isolated sections of the downcomer. A refueling lobe extends off of one side of the vessel. Incorporating design features common to the AHTR, SmAHTR, and the Mk1 concepts, the thinwalled vessel is suspended by a flange within a reactor silo. To keep the vessel wall temperature low, the primary coolant enters the reactor vessel through downcomer sections (defined by a core barrel) that direct the cold-leg coolant flow down to a lower plenum. The coolant flows up from the lower plenum to cool the fuel and core support structure.

Primary coolant enters the vessel at two inlet ports and is withdrawn from two outlet ports. Between the downward flowing downcomer regions, three smaller sections house the DRACS heat exchangers. The salt coolant inside the DRACS heat exchangers is independent and isolated from the reactor primary coolant. Two DRACS heat exchangers are part of an active safety system to remove decay heat from the system during loss of forced flow (LOFF) or loss-of-offsite-power events. The other heat exchanger is part of a passive DRACS and is intended to demonstrate passive safety features of a prototypic FHR.

A removable top hatch covers the vessel. Within the central portion of the top hatch, a smaller removable hatch houses the control drive mechanisms. Removal of the hatch, including the control drive mechanisms, allows for the insertion of a fuel manipulator for maneuvering of fuel within the vessel. The full top hatch can be completely removed for more extensive in-vessel modifications, including complete core exchange. New removable top hatch designs can be installed to facilitate new core designs or to allow access to new operating features such as flux traps or irradiation locations within the unfueled central or peripheral positions.

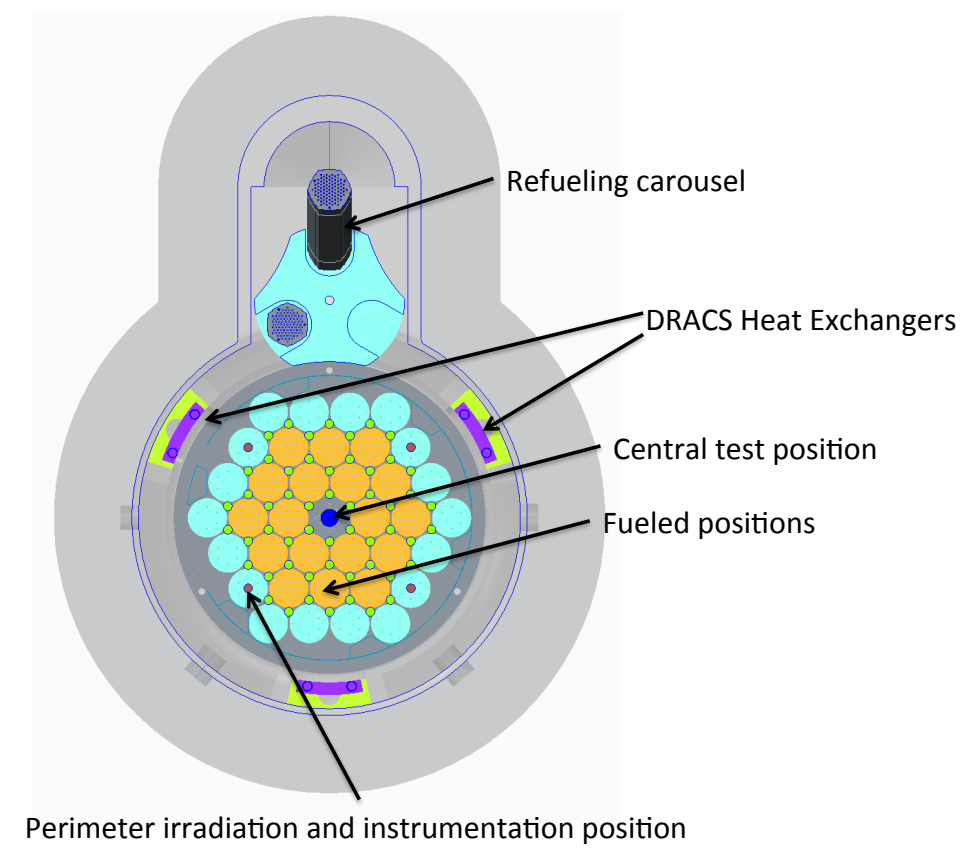

Fig. 10. Top view of the FHR DR core and vessel.

\subsection{HEAT TRANSPORT CONFIGURATION AND LAYOUT}

The heat transport systems consist of four salt pumps, two primary-to-intermediate salt-to-salt heat exchangers, and the associated primary and intermediate loop piping. It is intentionally designed to be simple, small, and distributed. Tritium management experiment stations are located between the reactor vessel and the primary-to-intermediate heat exchangers. Features of the PHTS are shown in Fig. 11 and 
listed in Table 4. The FHR DR uses alloy $800 \mathrm{H}$ lined with alloy $\mathrm{N}$ as structural materials for the primary and intermediate loops. The primary-to-intermediate heat exchangers are made from the same material combination. The use of similar materials throughout the system avoids the additional cost, complexity, and uncertainty of developing and operating high-temperature dissimilar metal heat transfer systems. The FHR DR incorporates tube-and-shell salt-to-salt heat exchangers because it is a relatively low-risk technology.

Tube-and-shell technology also allows for a swept interstitial region to be incorporated between the salts in a double-walled heat exchanger to limit tritium migration from the primary system to the intermediate system.

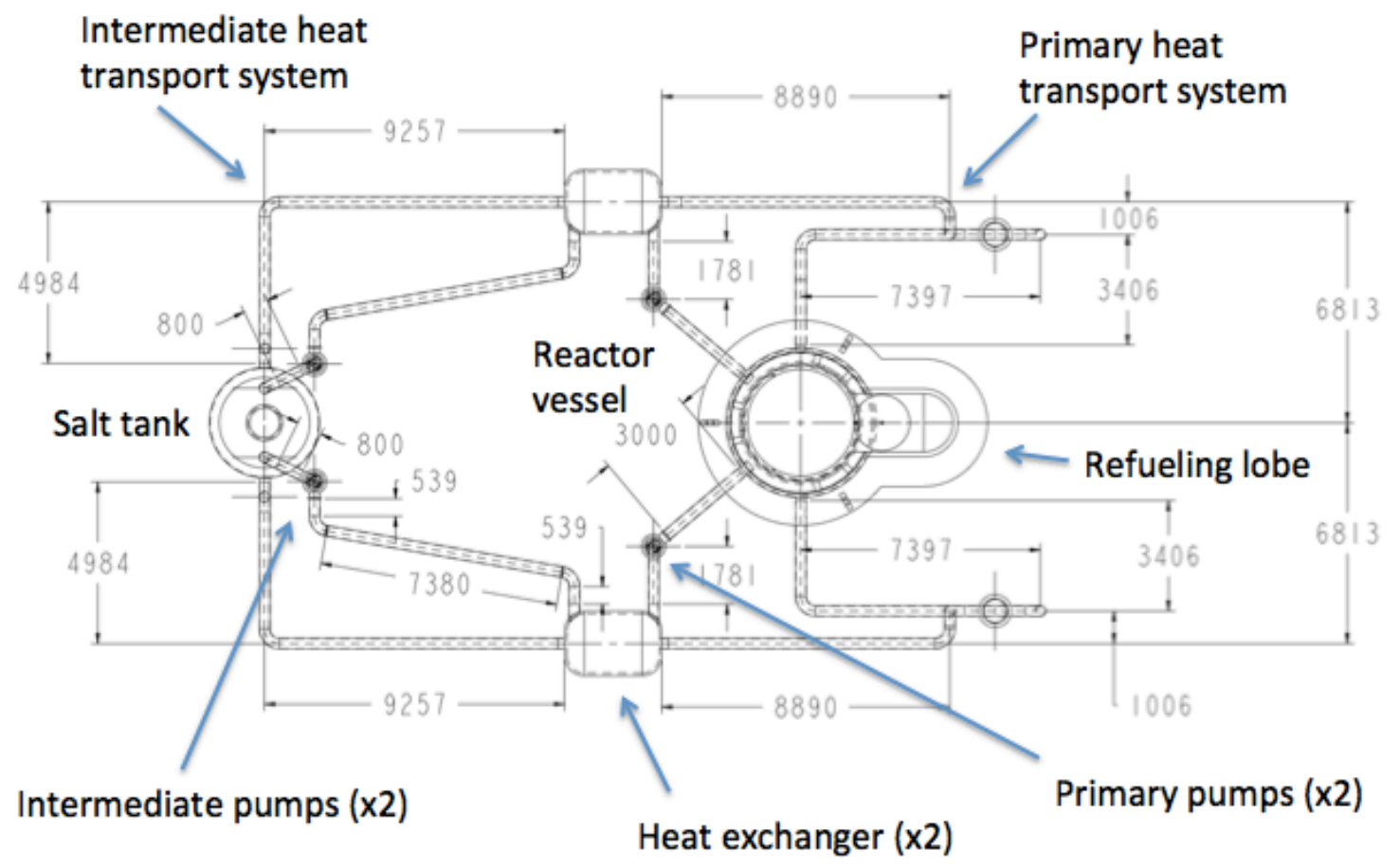

Fig. 11. FHR DR vessel and heat transport system layout.

Table 4. Primary heat transport system

\begin{tabular}{|c|c|c|}
\hline Parameter & Unit & Value \\
\hline Mixed mean core outlet temperature & ${ }^{\circ} \mathrm{C}$ & 701 \\
\hline Core inlet temperature & ${ }^{\circ} \mathrm{C}$ & 660 \\
\hline Number of fuel assemblies & & $\begin{array}{l}18 \text { fueled (baseline core, } \\
\text { configuration is flexible) }\end{array}$ \\
\hline Maximum fuel temperature (average assembly) & ${ }^{\circ} \mathrm{C}$ & 973 \\
\hline Vessel material & & Alloy $800 \mathrm{H}$ lined w/alloy $\mathrm{N}$ \\
\hline
\end{tabular}


Table 4. Primary heat transport system (continued)

\begin{tabular}{lcl}
\hline \multicolumn{1}{c}{ Parameter } & Unit & \multicolumn{1}{c}{ Value } \\
\hline Core fueled height & $\mathrm{m}$ & 2.61 \\
Core pressure drop for normal operation & atm & 0.6 \\
Primary coolant loops & - & 2 \\
Primary coolant & - & $2^{7} \mathrm{LiF}^{-\mathrm{BeF}_{2}}$ \\
Primary heat exchanger technology & - & Tube and shell (baseline) \\
Primary piping and heat exchanger material & - & Alloy $800 \mathrm{H}$ lined w/alloy N \\
Secondary coolant & - & FLiNaK \\
Power conversion system & & Open-air Brayton (baseline) \\
\hline
\end{tabular}

Consistent with the ORNL AHTR and SmAHTR concepts, the baseline salt for the intermediate heat transfer loop is FLiNaK, which was chosen as a compromise among heat transfer performance, melting temperature, handling issues, and cost. FLiNaK is also used in the DRACS for similar reasons, as well as the desire to limit the number of salt compositions used at the facility.

\subsection{REACTOR BUILDING AND AUXILIARY REACTOR SYSTEMS}

The reactor silo is the central feature of the FHR DR reactor building. It supports and protects the reactor vessel and serves critical operational and safety functions. The melting point of the primary coolant is $\sim 459^{\circ} \mathrm{C}$. To minimize the energy required to maintain melt temperatures, the vessel is surrounded by electrical resistance heaters, and insulation and is thermally isolated from the surrounding concrete by a dry, inert, gas-filled gap. The silo is lined with stainless steel, which serves as the secondary containment for primary salt if the vessel leaks. Additional resistance heaters warm ex-vessel structural components when the reactor is not operating, and coolant pumps distribute heat throughout the system. The vessel and heat transport systems must be protected if electrical power to the plant is lost. This is accomplished with auxiliary electrical generating equipment to cover short periods without grid power, and failsafe shutdown designs and methods are used for extended outages.

The reactor building houses the balance of the primary system one floor level below the reactor bay floor. The primary-to-intermediate heat exchangers, tritium experimental areas, and primary coolant pumps are housed on this lower level. Reactor fuel is staged on the main floor of the reactor building, and spent fuel is stored in isolated tanks away from the vessel. The top hatch and the control drive mechanisms are removed and stored in the bay during fueling operations. A crane-hoisted fuel transport cask is used to move fuel block assemblies within the reactor building. Fresh fuel block assemblies are stored in criticality control areas on the bay floor. Fuel is inserted into and removed from the vessel through the refueling lobe, and the fuel manipulator moves fuel between the lobe and the core.

Fresh fuel blocks are lowered into empty cylindrical positions within a rotating carousel in the refueling lobe. The carousel has vertical openings large enough to pass fuel blocks from the lobe into the vessel only when correctly aligned to do so. Otherwise the fuel is captured within the lobe. During reactor operation, the carousel is rotated to place a solid surface toward the core to complete the surface of the core barrel. This isolates fuel in the lobe from fuel in the core and allows, but limits primary salt mixing between the lobe and the vessel.

To remove spent fuel, the carousel is rotated to expose an empty location to the vessel. The fuel manipulator moves spent fuel into the carousel, which is then rotated to actively capture the fuel and isolate it from the vessel and core. Rotating the carousel further exposes a location filled with a fresh fuel block, and the fuel manipulator places the block in the correct core location. A fuel removal system is maneuvered over the refueling lobe by a crane in the reactor high bay, and a single spent fuel block is pulled into it. The spent fuel 
is moved over and lowered into an isolated salt storage vault on the reactor bay floor, where it remains until it can be moved first to a water tank and later to semi-permanent dry storage. The irradiated fuel handling device for the AHTR (left) and the three fuel storage tanks in relation to the vessel are shown in Fig. 12. The fuel manipulation strategy and equipment are identical to that proposed for AHTR.

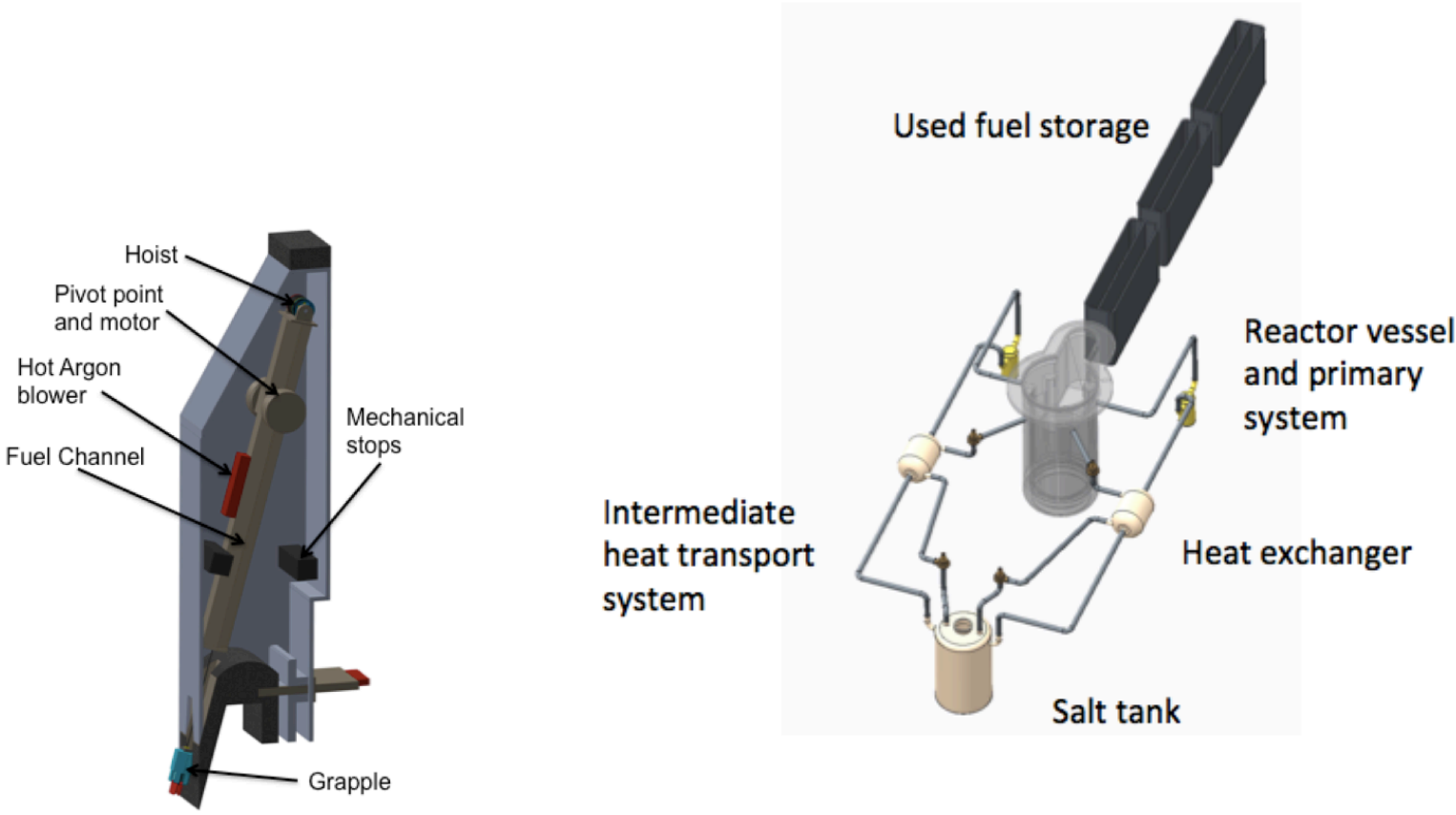

Fig. 12. Used fuel removal system (left) and the configuration used to store used fuel (right).

Piping passes out of the reactor primary system areas where radiation is higher and into an adjacent area which houses the balance of the intermediate heat transport system and heat use equipment. The waste heat rejection system is outside the heat handling area. Heated intermediate salt is deposited into an insulated storage vessel. It is possible to withdraw energy from this salt vessel and use it in a number of ways. Hightemperature forced-air heat exchangers to drive open-air Brayton cycle power systems are the reference baseline for what could eventually be a $42 \mathrm{MW}$ electrical generation application. Other high-temperature heat processes can be driven by placing salt-to-salt heat exchangers directly into the salt storage vessel. Lower temperature steam production can occur to produce electricity or drive a steam-based chemical process, or heat can also be rejected when other capabilities are not being demonstrated.

\section{SAFETY BASIS}

The FHR DR uses active heat removal systems to enable licensing and facility routine operation. Active safety systems are necessary to license the FHR DR in the near-term because adequate data do not exist to prove performance of passive salt-based heat removal safety systems for licensing purposes. Active heat exchangers are also used for heat removal during maintenance outages as proposed for integral FHRs such as the SmAHTR. FHR DR operation will demonstrate passive safety system operation and generate the data needed for licensing and deployment of passively safe commercial FHRs.

The reactivity coefficients of the FHR DR are a key inherent safety feature of the reactor system. The fuel temperature coefficient and moderator temperature coefficient are both negative. The void coefficient is 
negative or negligible throughout the cycle. The reactor can exhibit acceptable shutdown characteristics with MHC control materials. It is significant to note that the FHR DR is a low-pressure system, and FLiBe boils at approximately $1430^{\circ} \mathrm{C}$, and the vessel is surrounded by a protective guard vessel, which is sized to prevent fuel from becoming uncovered in the event of a vessel leak. A credible pathway to complete core voiding is highly unlikely.

The active safety heat removal systems for the FHR DR are the two primary loops and two intermediate loops with electrical backup for the pumps and the two active DRACS, which also have electrical backup. The passive system primarily considered for decay heat removal from an FHR in an accident situation is a natural circulation DRACS. The FHR DR uses two in-vessel heat exchangers as part of two independent active DRACS and a third in-vessel heat exchanger as part of a passive DRACS. Both the active and passive DRACS rely on upward flow restriction under normal operating conditions to limit upward bypass flow from the lower plenum to the upper plenum. When the DRACS is in use, flow over the heat exchangers reverses, and warm coolant from the upper plenum flows downward in the DRACS downcomer sections in a continuous circular path.

\subsection{SAFETY ANALYSIS OVERVIEW}

The FHR DR has a variety of safety features, including inherently negative reactivity feedback coefficients and a robust fuel form (TRISO). The well-established tools RELAP5-3D and TRACE were applied in the safety analysis of the FHR DR. Scarlat et al. (2014) was the basis for selecting the initiating events and transient scenarios studied in the FHR DR safety analysis. Analyses were performed to determine the potential response of the FHR to a variety of anticipated operational occurrences (AOOs) and design basis accident (DBA) events. These AOOs and DBAs included specific realizations of the following example event initiators (Scarlat et al. 2014):

(1) increase in heat removal from the primary coolant,

(2) decrease in heat removal from the primary coolant,

(3) decrease in reactor coolant system flow rate,

(4) reactivity accidents,

(5) increase in reactor coolant inventory,

(6) decrease in reactor coolant inventory, and/or

(7) radioactive release from a subsystem or component.

Specific example realizations of the events studied included LOFF with SCRAM, LOFF without SCRAM, overcooling transients, and reactivity-initiated accidents at hot full power and hot zero power conditions. Where appropriate, these transients were studied with neutron kinetics reactivity feedback. Although many events were considered, only two example events are presented in this report: a reactivity accident and a LOFF with SCRAM.

Comparisons were conducted between RELAP5-3D and TRACE models of the FHR DR. A multiple rod withdrawal event at hot full power (HFP) was simulated with RELAP5-3D and TRACE using kinetics feedback to simulate the reactor power over time. A reactivity worth of $0.58 \$$ was used for the inadvertently withdrawn rods, and a Doppler reactivity coefficient of $-0.0043 \$ / \mathrm{K}$ was used based on reactor physics calculations for the FHR core. The pumps operated at 100\% flow conditions throughout the event. Simulation results for the HFP rapid multiple rod withdrawal event are shown in Fig. 13. RELAP5-3D predicted a peak power of $229.9 \mathrm{MW}$ during the initial power spike versus a predicted peak power of 219.5 MW in TRACE. Both codes predicted similar behavior and settled to essentially the same asymptotic power level afterwards, demonstrating good agreement. 
Given the nature of the FHR DR (a low pressure system), this rapid (step insertion) multiple rod withdrawal event is not a credible scenario. This event was modeled to demonstrate agreement in the reactivity feedback parameters in the RELAP5-3D and TRACE models. This example demonstrates the capability of both RELAP5-3D and TRACE to provide a simulation of postulated safety events for the FHR DR system with thermal hydraulic feedback, and it also illustrates how code-to-code comparison studies were leveraged to enhance confidence in the results of the safety analysis. An additional comparison (which is not included in this report) was conducted for a hot zero power super prompt critical reactivity insertion. When compared to a Nordheim-Fuchs analytical solution the RELAP5-3D and TRACE models showed good agreement between models.
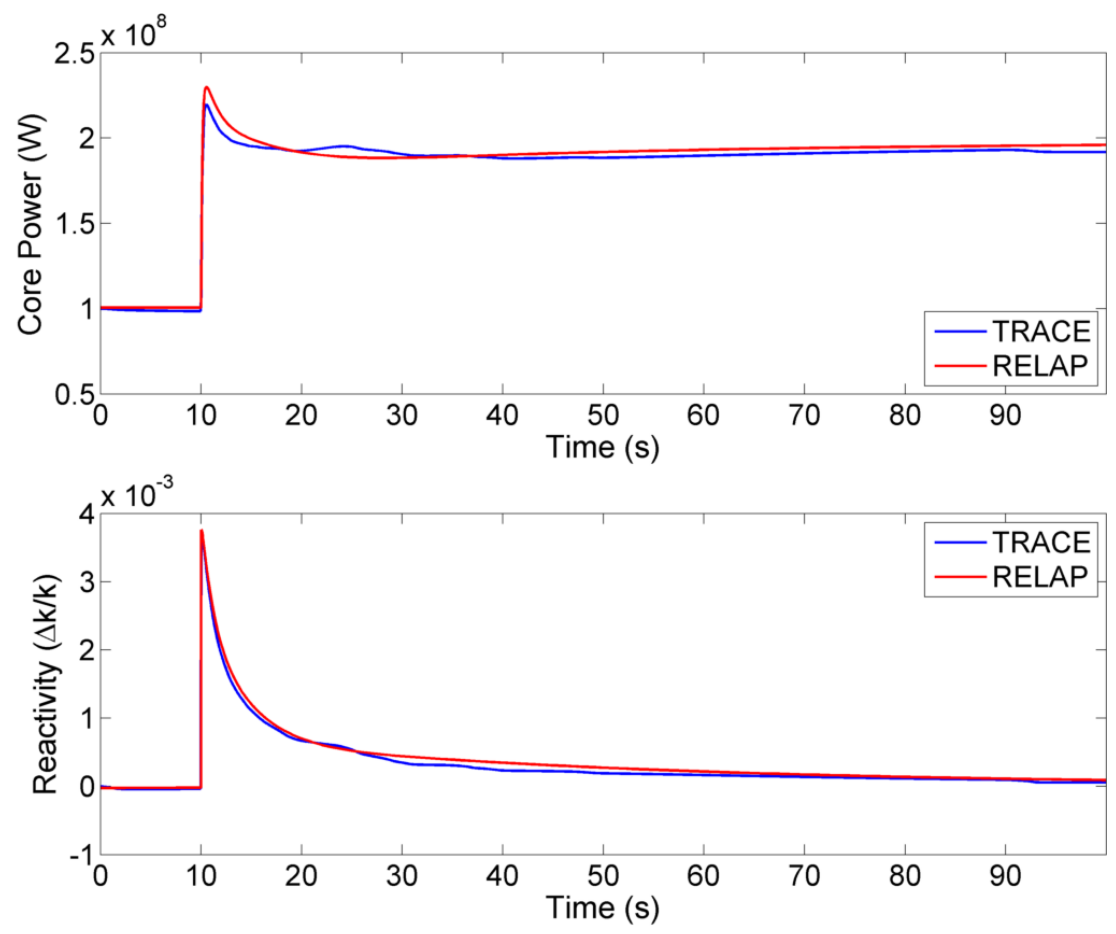

Fig. 13. Comparison of reactor power (top) and reactivity (bottom) calculated by TRACE and RELAP5-3D for the HFP rapid multiple rod withdrawal event.

Example transient results from an LOFF transient with SCRAM are shown in Fig. 14. This analysis assumes that one of the active DRACS is inoperable but that the other active DRACS and the passive DRACS are operating. The predicted coolant temperatures during the transient and suggests that temperatures remain well below the melting temperature of Alloy $800\left(1325^{\circ} \mathrm{C}\right)$. Benefitting from the low pressure system and the high temperature strength properties of Alloy $800 \mathrm{H}$, the vessel is designed to avoid damage during LOFF or other scenarios. 


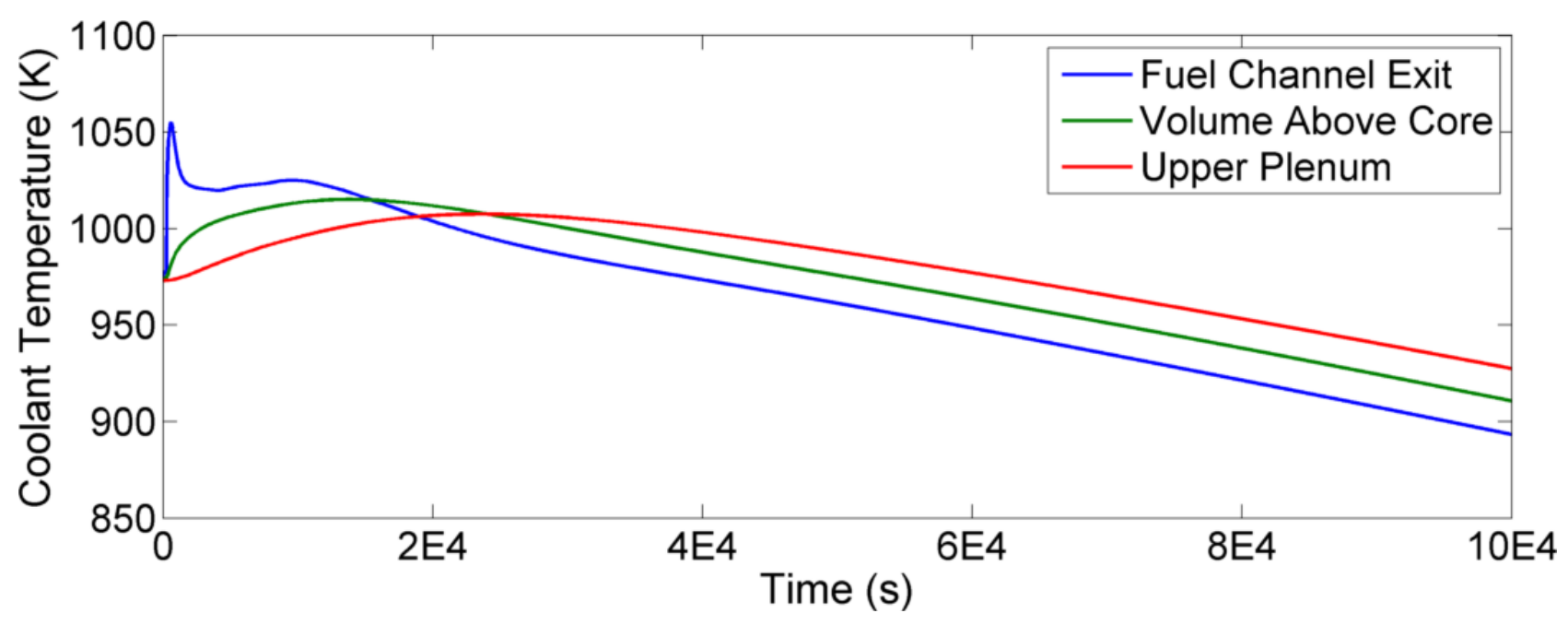

Fig. 14. RELAP5-3D calculated coolant temperatures during a LOFF transient with SCRAM.

\subsection{INSTRUMENTATION AND CONTROL DRIVE MECHANISMS}

The FHR DR will serve as a demonstration testbed for commercial technologies. These technologies will be instrumented for high resolution spatial and dynamic response. For pumps and reactivity control drives, temperature, electrical, and mechanical sensors will gather data on performance for comparison to performance prediction models. Neutronic measurements will spatially resolve reactor core response to reactivity control actions. The FHR DR passive DRACS contains instrumentation packages that allow the behavior of that system to be fully characterized. The high-quality data will relate ambient environmental conditions to temperature and flow conditions within the reactor vessel and within the passive DRACS system so that detailed analysis of system performance can be used to design and license future passively safe commercial concepts.

FHR control instrumentation has two significant technical differences from existing reactor classes: high temperatures and salt. Materials compatible with higher temperature and salt can be applied to traditional instrumentation to accommodate many FHR measurement needs. Salt chemistry instrumentation must be developed and qualified for application in a reactor.

The particular characteristics of FHR reactors have been recognized, and nontraditional measuring techniques are under consideration, but they require further development. These characteristics include a transparent, low-pressure coolant which increases the opportunity to employ remote measurements. The development of these techniques requires developing and demonstrating components compatible with the FHR environment such as lenses, mirrors, and windows. Activities to develop and demonstrate instrumentation will be part of both a component and system level separate effects activity.

The reactivity control system consists of a driving motor at the top of the reactor's upper containment dome, concentric telescoping drive mechanisms within the dome, detachable control rods within the vessel, and the seals that permit the drive to pass through each isolated volume. Fifty four (54) individual absorbing rods are used to regulate the reactor fission power. Using the large number of control rods puts one rod at each block corner and allows each hexagonal fuel or reflector block to be identical in shape. Additionally, these "gray rods" allow fine tuning of the power shape, a key feature that can be used to tailor flux or power distributions to meet various demonstration or experimental needs. The rods are grouped together in sizes that limit the reactivity value of potential inadvertent control rod withdrawal or rod ejection scenarios. The assumption is that 18 control rod groupings are used to control the reactor. Of that number, twelve rods are fully withdrawn during normal operation, and six are used to regulate power within the core during normal operation. 
The FHR DR uses control drive technology derived from the HFIR, which consists of control cylinders, inner drive rod assemblies, seal housings, a lead screw, shim gearbox, regulating gearbox, servo gearbox, pressure balance cylinder, and shim, regulating position indicators, and associated controls. The safety boundary of each drive is considered to include all the mechanical components from the control cylinder up to and including the pressure-balance cylinder. The servo, regulating, and shim gearbox assemblies are considered defense-in-depth due to their influence on control cylinder withdrawal speed. Withdrawal speed is a safety analysis report (SAR) analysis parameter. The shim and regulating position indicators are evaluated as defense-in-depth due to the important information provided to the operators. The heat power instrumentation is defense-in-depth because it is a part of the reactor power and primary temperature controls. The servo control system and associated electrical equipment are considered defense-in-depth because sufficient isolation exists to protect the safety system. These systems would not be credited with accident mitigation in an eventual SAR. The defense-in-depth function of the cylinder position indicator is to provide control cylinder position. Control drive systems also include the mechanical equipment necessary to achieve SCRAM of the reactor. An absorber salt injection system is the current baseline for a diverse secondary shutdown system.

\section{TECHNOLOGY READINESS}

The FHR DR fuel form was selected based on an assessment of the potential for deployment within 10 years. The fuel form is based on the well-understood prismatic graphite block with integral coolant channels and TRISO fuel compacts. Several recent salt-cooled reactor concepts also rely on TRISO fuel particles in various graphite fuel forms. The UCB Mk1 concept uses fuel pebbles in a packed bed, the SmAHTR concept assumes TRISO particles in fuel planks, and the MIT FHR test reactor design uses prismatic fuel blocks similar to HTGR fuel. Although developed for higher operating temperatures, some TRISO fuel qualification irradiation conditions appear to be relevant to the anticipated conditions of the FHR DR TRISO fuel and are considered mature technology for this application.

FHR concepts may benefit from advanced nonmetal materials that form some of the plant's lifetime or invessel structural components, but these materials are not yet qualified for use in reactors. The FHR DR approach to accommodate near-term deployment is borrowed from the UCB Mk1 concept of making critical core structures removable and replaceable along with used fuel. The reactor vessel is designed with a bolted core structure interface to allow new and potentially different core structures to be operated within the same facility. The structural materials holding fuel blocks together are the same materials used for the reactor structure and are thus considered mature. This ensures that they will function, but they are not optimal with respect to core neutronic performance. Advanced structural materials or material combinations will be investigated to reduce the amount of parasitic neutron absorbing material within the core.

Pumps, heat exchangers and instrumentation hardware can be adapted from other nuclear and industrial applications but need to be specifically applied to the materials and operating conditions of an FHR. Structural material fabrication and qualification will require considerable development. Additional FHR technology demonstration needs include the ability to handle and maintain the required salts and operate the plant remotely and with as much automation as possible. This may include the ability to remove, inspect, maintain and install heat exchange and pumping equipment after operation. Tritium management is a key challenge with FHRs. Research, development, and demonstration of tritium management methodologies will occur in a separate focused effort. The FHR DR will follow the tritium management protocols established within the fusion research community through many decades of research, but these will require adaptation. 


\section{LICENSING, DEVELOPMENT AND DEPLOYMENT PLANS}

The FHR DR replicates the safety characteristics and has prototypic systems and components expected in a commercial plant. These include high boiling temperature and low-pressure coolant, large operating margin to allowable fuel temperature during anticipated occurrences and accident sequences, inherently negative reactivity coefficients in the core design (including void coefficient), active and passive decay heat removal systems, and redundant and diverse shutdown systems. The reactor building is equipped with tritium monitoring and management systems to limit the release of tritium to the environment to allowable levels.

The FHR DR development strategy is illustrated in Fig. 15, along with preliminary cost estimates for each activity. This is an optimistic and notional 10-year schedule that includes ongoing research and development, in addition to new SET facilities permitting collection of specific physical data on salt and material interactions. Large component flow test facilities must also be developed to help determine how technologies will scale to commercial power levels in relevant environments. These facilities must be deployed in conjunction with the development of computational tools targeted toward licensing to ensure that the appropriate data will be collected. In parallel to these activities, reactor design must progress through conceptual and preliminary designs. Data collected from test facilities will be used to complete final design. Early design efforts benefit from existing data, ongoing research initiatives, and operational experience of the MSRE. Thus it is reasonable to presume that (1) effective design can occur as the test facilities are set up and become operational and (2) the reactor can be operational within a decade of a decision to proceed. This schedule estimate assumes that focused research and development will continue within the national laboratory and university systems and that it will be complemented with new and necessary separate development and testing immediately after the decision to proceed. Data from these larger scale projects will begin to inform preliminary design efforts within 2 or 3 years of being commissioned. The final design phase will be approximately 3 years. The construction period is expected to range from four years (comparable to that of HFIR) to seven years (similar to that of large commercial LWRs). 


\begin{tabular}{|c|c|c|c|c|c|c|c|c|c|c|c|c|}
\hline Development & & 1 & 2 & 3 & 4 & 5 & 6 & 7 & 8 & 9 & 10 & $\mathbf{\$ M}$ \\
\hline & fuel design and qualification & & & & & & & & & & & 50 \\
\hline & lithium enrichment & & & & & & & & & & & 50 \\
\hline & structural material development & & & & & & & & & & & 50 \\
\hline & structural material testing and qualification & & & & & & & & & & & 50 \\
\hline & pump design and testing & & & & & & & & & & & 50 \\
\hline & heat exchanger development & & & & & & & & & & & 50 \\
\hline & instrumentation system design & & & & & & & & & & & 50 \\
\hline & tritium management & & & & & & & & & & & 50 \\
\hline & remote handling system development & & & & & & & & & & & 50 \\
\hline & & & & & & & & & & & & 450 \\
\hline \multicolumn{13}{|l|}{ Design } \\
\hline & conceptual design development & & & & & & & & & & & 50 \\
\hline & engage vendor/AE firm & & & & & & & & & & & 100 \\
\hline & prelliminary & & & & & & & & & & & 50 \\
\hline & final & & & & & & & & & & & 100 \\
\hline & & & & & & & & & & & & 300 \\
\hline \multicolumn{13}{|l|}{ Licensing } \\
\hline & discovery and definition & & & & & & & & & & & 10 \\
\hline & authorization to begin site preparation & & & & & & & & & & & \\
\hline & gathering of required data & & & & & & & & & & & 90 \\
\hline & authorization to begin construction & & & & & & & & & & & \\
\hline & preparation of final documentation & & & & & & & & & & & 50 \\
\hline & submittal/review, authorization to operate & & & & & & & & & & & 100 \\
\hline & & & & & & & & & & & & 150 \\
\hline \multicolumn{13}{|l|}{ Construction } \\
\hline & site preparation & & & & & & & & & & & 100 \\
\hline & building construction & & & & & & & & & & & 200 \\
\hline & system installation & & & & & & & & & & & 200 \\
\hline & & & & & & & & & & & & 500 \\
\hline \multicolumn{13}{|l|}{ Pre-nuclear operation } \\
\hline & salt loading and purification & & & & & & & & & & & 50 \\
\hline & electrical heating and flow testing & & & & & & & & & & & 50 \\
\hline & & & & & & & & & & & & 100 \\
\hline Nuclear operation & & & & & & & & & & & & 1500 \\
\hline
\end{tabular}

Fig. 15. Combined FHR DR notional deployment timeline (in years) and cost.

DOE operates two reactors, HFIR and ATR, both of which were initially certified and regulated under the US Atomic Energy Commission. With the passage of the Price Anderson Act in 1987, liability to operate these facilities created the need to revisit certification. 10 CFR 820 and 830 address certification of these reactor facilities. These rules reference the use of NRC RG1.70 for the safety basis evaluation of nuclear facilities for authorization. Both HFIR and ATR were recertified under this process, and SARs were developed that are consistent with the requirements of RG1.70. Any future authorization for a DR could follow one of several paths. DOE can choose to certify (license is a term used only for NRC approval) the operation of a DR following the existing rule and using RG1.70. However, RG1.70 is an NRC document that is no longer used by the NRC. Additionally, DOE has stated that the existing manpower and expertise to certify a new design does not exist within DOE. Therefore, the more likely path would be for DOE to either (1) cede the certification (or licensing) to NRC or (2) contract with NRC to review the certification package against the requirements of RG1.70 as stipulated by 10 CFR 830 .

Under the first scenario, NRC would grant a license for operation based on the facility's classification as either a power reactor (type 103 license) or a test reactor (type 104 license). In this case, NRC's licensing follows either 10 CFR 50 or 10 CFR 52-most likely 10 CFR 50. For the purposes of licensing, 10 CFR 50 defines a type 103 license to be associated with facilities that generate a sufficient amount of operating revenue $(50 \%)$ from power production or sales. However, the NRC practical position may be that a nuclear reactor attached to an energy conversion system will constitute a power reactor. This is a crucial distinction, as the requirements for the power reactor versus test reactor licenses under NRC are considerably different. Non-power reactor licenses follow NUREG-1537 requirements and do not have to meet the general design 
criteria promulgated in the Code of Federal Regulations. Rather, a phased approach to criteria is specified in NUREG-1537 based on the operating power level. Critical considerations associated with siting and emergency plans and operations are exempt under the test reactor license. These can have long lead times and can considerably delay the licensing process.

In the second scenario, DOE could contract with NRC to review and recommend a certification package for the DR. In this case, by current rule, the package would be required to undergo review against the requirements of RG1.70. Although NRC apparently no longer follows RG1.70, a review could be conducted against this document and recommended to DOE. Alternatively, DOE could follow rulemaking procedures and amend the rule to reference more recent NRC guidance on licensing requirements. The decision to do this would be based on negotiations between DOE and NRC to resolve any issues NRC has with reviewing against a legacy document that is no longer in effect. It is worth noting that as long as NRC is recommending and not licensing, DOE would have latitude to define requirements so long as they are consistent with 10 CFR 830. In particular, this would avoid the semantic distinctions associated with test reactors versus demonstration reactors. While NRC does not draw a distinction between demonstration reactors and power reactors, DOE draws a distinction that differs from NRC definitions. Any ceding of licensing to NRC could create conflict between both agencies' definitions and expectations for the use and operation of the proposed facility; this could negatively impact licensing strategy, time frame, and success.

The safety of the FHR is based on significant margins in the FHR design, where (Forsberg et al. 2014c):

[t] he potential to avoid major fuel failures under extreme accident conditions in large FHRs is a consequence of the unique combination of the high-temperature properties of the fuel and coolant. The FHR uses HTGR graphite-matrix coated-particle fuel with failure temperatures of $>1650{ }^{\circ} \mathrm{C}$. The coolants are clean fluoride salts that have melting points above $350^{\circ} \mathrm{C}$ and boiling points above $1400{ }^{\circ} \mathrm{C}$. These high temperature limits relative to other nuclear fuels and coolants may enable systems to be designed to prevent major fuel failures in large FHRs in severe accidents.

Based on technology developed for ITER, active systems monitor and capture free tritium within the FHR DR atmospheres. These systems will be sized to limit the maximum credible tritium release during severe accident scenarios to acceptable levels. The data related to predicting this maximum credible event are not complete, although it is known that the FHR DR will produce and hold far less tritium than ITER will handle. Therefore, presumably, exclusion zones can be predicated on fuel damage expectations, which are deemed incredible. For DOE, determination of the emergency planning zone (EPZ) is based on DOE O151.1C. The EPZ for facilities at ORNL (including HFIR) can be found in the standards based management system (SBMS) subject area, "Emergency Preparedness and Response." HFIR is authorized to operate based on the RG1.70 safe harbor approach. Licensing calculations for dose consequence are based on 10 CFR 100 limits of 25 rem for whole body and 300 rem for thyroid. Because HFIR has dynamic confinement rather than containment, conservative estimates of the maximum possible dose following an assumed two-hour release (i.e., no substantial credited building holdup of fission products) of the entire contents of the core are identical with estimates for "the entirety of the passage of the plume." As a result, HFIR has a colocated exclusion area and low population zone, both of which have been identified with the Oak Ridge Reservation site boundary. This same approach is likely for the FHR DR, which is presumed to be located on a large DOE reservation. Given an incredible fuel damage scenario and active tritium containment systems, the emergency planning zone for the FHR DR is assumed to be less than $400 \mathrm{~m}$. 


\section{ECONOMICS AND SCHEDULE}

The FHR DR benefits from a significant amount of demonstrated technology. The TRISO fuel particle is mature based on historic and current ongoing programs for the high temperature reactor programs. Alloy 800 is approved for use in reactors and is proposed for use within the higher temperature and pressure gas reactor systems. MSRE demonstrated the ability to produce and manage FliBe salt chemistry and operate at reactor outlet temperatures of $663{ }^{\circ} \mathrm{C}$. These technologies will require qualification for specific use in the FHR DR, but they are already demonstrated at or near the service levels anticipated for FHR DR. Less mature technologies or those demonstrated only at the smaller MSRE scale (i.e., pumps, heat exchangers, and instrumentation) also require development activities. Specifically, tritium handling system development and demonstration, although leveraged against other DOE programs, will be a significant effort. Qualification of materials and processes, development of remote maintenance capability, and code development, verification and validation are well understood activities but will also require investment. A rough estimate of the FHR DR development cost, as presented in Fig. 15, is approximately $\$ 450 M$.

The costs associated with building an FHR DR are grouped as development activities, including materials and fuel qualification, design, licensing, construction, and operation. The intention is to keep the cost as low as reasonably possible and be operational as soon as practical with a committed effort. The strategy to keep the costs low includes (1) use of available materials, (2) keeping the system simple and small, and (3) having a robust safety posture that minimizes the need for safety critical components and systems to the extent possible. The fuel is derived from a well-characterized fuel form but will require qualification for use in the FHR DR. The main difference in the fuel's intended use is the use of it in salt. The compatibility of graphite and nickel-based alloys in fueled FLiBe salt was confirmed at MSRE. However, the addition of fuel to the salt provided an efficient means of controlling the salt chemistry and limiting structural material corrosion. For the FHR DR, a separate salt chemistry control system will require development and demonstration, and compatible graphite materials must be identified and tested. The coolant is a low-pressure coolant to allow structural components to be thin-walled. The primary alloy is Alloy 800, an approved material for nuclear applications. The alloy will require a coating or a liner to be used with the salts. This technology must be developed and confirmed for the FHR DR. Fabrication techniques to incorporate the protective technology must be developed for all needed applications. This includes the reactor vessel (the largest component), piping, and importantly, any welds used in the system. The use of temporary connections (flanges) for connecting piping or allowing penetrations into the vessel and piping systems must also be investigated.

The FHR DR will demonstrate two important new capabilities; the cost and time to develop these items are difficult estimate. Perhaps the most significant FHD DR development issue is the management of tritium. Although a number of techniques appear feasible, significant development effort remains, and the actual performance of reactor scale systems will not be fully known until the reactor is operational. Another significant issue is the passive safety response of salt DRACS systems. The FHR DR incorporates active, redundant, and diverse heat removal systems to ensure a straightforward safety and licensing case. FHR DR operation will permit testing of the passive DRACS in an effort to demonstrate a fully passive response to off-normal occurrences.

Even when considering the use of low risk strategies, it is difficult to estimate the cost of building the FHR DR because it is a FOAK reactor system. Issues include the uncertainty in the licensing process, the ability to develop necessary fabrication methods, and the ability to gather sufficient data to justify their use. The ability to obtain the sizable quantities of enriched lithium needed for the primary coolant is perhaps one of the largest uncertainties. The estimated costs for the FHR DR are listed by category in Table 5 and discussed below. 
Table 5. Nominal scoping cost estimates for FHR DR deployment without contingency

\begin{tabular}{|c|c|c|}
\hline Item & $\begin{array}{c}\text { Rough cost } \\
\text { estimate }\end{array}$ & Scope \\
\hline Development & $\$ 450 M$ & $\begin{array}{l}\text { Effort over multiple areas including material compatibility, } \\
\text { code development, and tritium management }\end{array}$ \\
\hline Design & $\$ 300 M$ & Comparable to presumed SMR costs \\
\hline Licensing & $\$ 150 M$ & Assumed paid to the licensing agency \\
\hline Capital cost & $\$ 500 M$ & Based on various methods of approximation \\
\hline $\begin{array}{l}\text { Salts procurement and system } \\
\text { preparation }\end{array}$ & $\$ 100 M$ & Lithium enrichment costs are not certain \\
\hline Operations & $<\$ 100 M$ & Based on HFIR costs of $\sim \$ 65 \mathrm{M} /$ year \\
\hline
\end{tabular}

A capital cost estimate for the AHTR used the Generation IV International Forum cost estimation methodology implemented in G4ECONS based on escalated historic pressurized water reactor (PWR) capital costs as its initial basis (Holcomb et al. 2011b). Because these costs were based on a preconceptual design rather than a detailed design, adjustments were made to the detailed LWR costs estimate to reflect AHTR technologies. The results show a total overnight capital cost of $\sim \$ 4.5$ billion or for the $3400 \mathrm{MWt}$ AHTR or $\sim \$ 1300 / \mathrm{kWt}$ as an Nth-of-a-kind (NOAK) cost. Converting a NOAK cost to a FOAK cost requires assumptions on the benefit (if any) of learning curves and the number of units required to achieve the NOAK cost. Several estimates (Rosner 2011) on reactor learning curves using modular construction and factory fabrication give an approximate value of a 10\% decrease for each doubling, and a reasonable estimate for the "N" to achieve NOAK is $\sim 16$. Thus, reactor 16 achieves NOAK, reactor 8 achieves NOAK/0.9, reactor 4 achieves NOAK/0.81, reactor 2 achieves NOAK/0.729, and the FOAK costs NOAK/0.6561. This results in FOAK costs of $\sim \$ 2000 / \mathrm{kWt}$ for the $3400 \mathrm{MWt}$ AHTR concept. Finally, accounting for size scaling from $3400 \mathrm{MWt}$ to $100 \mathrm{MWt}$ in different work breakdown structure categories yields a cost range of $\$ 2050 / \mathrm{kWt}$ to $\$ 6800 / \mathrm{kWt}$. Rounding up for conservatism gives a range of $\$ 2500-7000 / \mathrm{kWt}$ for the FHR DR's total capital cost.

A second, essentially independent source for the capital cost estimate for the FHR DR comes from the Advanced Fuel Cycle Cost Basis (Shropshire et al. 2009). This periodic report includes capital and operation cost for multiple reactor types based on multiple sources. For the 2012 addendum to the cost basis, a solidfueled salt-cooled reactor type was added to the reactor modules. The cost estimate in the cost basis for a solid-fueled salt-cooled reactor is given as a triangular function with a low, mode, and high value of $\$ 2000$, $\$ 5000$, and $\$ 8000 / \mathrm{kWe}$, respectively. However, these are given in $\$ / \mathrm{kWe}$ as opposed to $\$ / \mathrm{kWt}$, which is more appropriate for the cost estimation of a research reactor. Using an assumed thermal efficiency of $42 \%$, the capital costs are then approximately $\$ 800, \$ 2000$, and $\$ 3200 / \mathrm{kWt}$, respectively. This cost basis also assumes NOAK costs rather than FOAK costs. Using the learning curve information described above, the capital cost range for a FOAK solid-fueled salt-cooled reactor is approximately $\$ 1200, \$ 3000$, and $\$ 5000 / \mathrm{kWt}$ and are generally within the range of the costs from the AHTR estimates.

Cost estimates performed for similar designs are another independent source of potential cost information. One design similar to the FHR DR is the UCB Mk1 PB-FHR (called simply Mk1) (Andreades et al. 2014 and 2015a). The Mk1 is a $100 \mathrm{MWe}(236 \mathrm{MWt})$ reactor intended to be coupled with a natural gas combined cycle plant to increase efficiency. UCB produced a detailed cost estimate for the Mk1 using a full bill of materials for both the reactor and a coupled natural gas plant (Andreades 2015a). Their study also assumed NOAK costs. The capital cost estimates for the Mk1 yield a value of $\sim \$ 5000 / \mathrm{kWe}$, which translates to $\sim 2100 / \mathrm{kWt}$ for the NOAK. Using a translation to a FOAK similar to that performed above, the FOAK cost is $\sim \$ 3200 / \mathrm{kWt}$. This matches well with the previous estimates. 
Summarizing the results from these studies, construction costs range from a nominal value of $\$ 3,000 / \mathrm{kWt}$ to an upper end value of $\$ 7,000 / \mathrm{kWt}$. Thus, using three separate methods, the FHR DR has a capital cost range of $\sim \$ 300-\$ 700 \mathrm{M}$. For the purposes of this effort, a capital cost of $\$ 500 \mathrm{M}$ above the mean of the cost range is assumed until more design detail is available to produce a better estimate. When combined with the estimates for development cost, design cost, licensing cost, and salt procurement cost, the extrapolated project cost estimate is approximately $\$ 1.5$ billion.

There is considerable uncertainty associated with reported capital cost estimates (as opposed to total project costs) in terms of their accuracy, what was included in the estimate, and its relevance to today's regulatory environment. The values derived from these independent methods produce fairly consistent results and appear to be consistent with costs quoted for several modern research reactors of comparable size, such as the 65 MWt China Experimental Fast Reactor (CEFR) sodium fast reactor ( $\$ 400 \mathrm{M})$ (Yang 2013) and the MYRRHA accelerator driven mixed-fuel $100 \mathrm{MWt}$ lead-bismuth system (\$1000 M) (MYRRHA 2016).

Given that there is no operating experience with FHRs, an operating cost is difficult to estimate and is best based on the operating costs of similarly sized operating reactors. Three components are to be considered for the net operating costs: fuel costs, non-fuel operations costs, and income from electricity generation.

The trend of reactor non-fuel operations costs shows that the annual per-kWt cost increases nonlinearly as the size of the reactor decreases; this is expected since staffing does not scale linearly with the size of the reactor. The 2014 non-fuel O\&M cost averaged for the current LWR fleet is approximately $\$ 0.0164 / \mathrm{kWe}-\mathrm{hr}$ (NEI), which for a 1 GWe LWR would result in an annual O\&M cost of $\$ 160 \mathrm{M}$. On the other hand, the annual non-fuel costs for the operations of the $85 \mathrm{MWt}$ ORNL HFIR reactor is approximately $\$ 60 \mathrm{M}$. Given the nonlinearity with reactor size, the lack of data, and the similarity in size of HFIR to the FHR DR, the HFIR operations cost is taken as the nominal cost resulting in a non-fuel O\&M cost of \$76/MWt-h. A scoping assessment of the HFIR operating budget concluded that the majority of operating costs would also be expected for the FHR DR. Combining the fuel costs and O\&M costs produces a total operating cost estimate of $\$ 72 \mathrm{M} / \mathrm{yr}$ or $\$ 91 / \mathrm{MWt}-\mathrm{h}$. Given that the demonstration could eventually produce electricity, some operating costs can be recovered by the electricity sales. Assuming $42 \%$ conversion efficiency and selling electricity at the industrial price of $\$ 69 / \mathrm{MWe}-\mathrm{h}$, operations would be offset by approximately $\$ 29 / \mathrm{MWt}-\mathrm{h}$. Thus, the estimated operating costs range from $\$ 62 / \mathrm{MWt}$ - $h$ with electricity sales to $\$ 91 / \mathrm{MWt}$ - $h$ with no electricity sales. These operating cost estimates can be compared to those prepared for the $236 \mathrm{MWt} \mathrm{Mk} 1$ PB-FHR of $\$ 71 \mathrm{M} / \mathrm{yr}$ (Andreades 2015b).

\subsection{FUEL}

The FHR DR fuel costs include costs for mining, milling, and conversion; enrichment; depleted uranium disposal; and fuel fabrication costs. Assuming the long-term expected values from the Cost Basis for mining, milling, and conversion ( $\sim \$ 150 / \mathrm{kgHM})$, enrichment ( $\sim$ 100/separative work unit), depleted uranium (DU) disposal $(\sim \$ 6 / \mathrm{kgDU})$, and TRISO fabrication $(\sim \$ 13 \mathrm{k} / \mathrm{kgHM})$, the fuel cost per $\mathrm{kgHM}$ for TRISO fuel is $\sim \$ 21 \mathrm{k} / \mathrm{kgHM}$. The fabrication cost accounts for $\sim 60 \%$ of the total cost, with the other $40 \%$ split evenly between enrichment and material handling. Depending on whether the operation strategy is one-batch or three-batch, the annual fuel cost ranges from $\sim \$ 6 \mathrm{M}$ (three-batch, highest-burnup) to $\sim \$ 15 \mathrm{M}$ (one-batch, lowest-burnup). Using \$10M as the expected value yields fuel cycle costs of \$11/MWt-h. The high uncertainty in TRISO fabrication costs implies a large uncertainty in fuel cost aside from the differences in operating strategy.

A recent study of FHR fuel cycle cost was completed as part of the Georgia Tech Integrated Research Project (Kingsbury 2015). The study projected costs of $\$ 39.8 / \mathrm{MWe}-\mathrm{hr}$ for a single batch FHR core with conservative fuel fabrication costs of $\$ 24,000 / \mathrm{kgU}, 15 \%$ enrichment, a TRISO particle packing fraction of 0.3 , and an outage cost of $\$ 20$ million. Within this estimate, the majority of the cost is fabrication, followed 
by material, and quality assurance. Using these estimates from Kingsbury (2015), total fuel cycle cost is approximately \$16/MWt-h. However, Kingsbury (2015) notes that the fuel fabrication cost assumption of $\$ 24,000 / \mathrm{kgU}$ is conservatively expensive.

An estimate of the FHR DR fuel costs can also be obtained from data in the Advanced Fuel Cycle Cost Basis (Shropshire et al. 2009), which provides a nominal TRISO fuel fabrication cost of $\$ 10,000 / \mathrm{kgU}$ and mean of $\$ 15,000 / \mathrm{kgU}$. Assuming the nominal value and UxC long-term prices (WISE Uranium Project 2016) longterm prices for uranium, conversion, and enrichment, and a $643 \mathrm{kgU} / \mathrm{yr}$ requirement for a once-through, single batch core with nickel-based (Alloy $800 \mathrm{H}$ ) structural materials, the annual fuel costs are approximately $\$ 12 M /$ year, or $\$ 15 / M W t-h$.

\subsection{SALT}

A significant uncertainty in the cost of salt procurement is the cost to enrich lithium to the levels required. Enrichment is an important factor in the rate of tritium production, and levels approaching $99.995 \%$ are desirable. New methods are under development for the low cost production of enriched lithium. However, to date, these methods have not been demonstrated beyond a laboratory scale. The salts and salt handling remain a significant unknown in terms of both initial and operational costs. The FHR DR uses FLiBE as the primary coolant and FLiNaK as its secondary coolant. Several cost estimates have been generated for these salts; the most recent cost estimates are for FLiBe only, but Sanders also includes FLiNaK. The values assume $99.995 \%$ enriched ${ }^{7} \mathrm{Li}$. Table 6 lists the values.

Table 6. Cost estimates for salts $(99.995 \%$ enriched lithium)

\begin{tabular}{cccc}
\hline Salt & Source & Cost $\mathbf{( \$ / k g )}$ & Escalated cost $\mathbf{( \$ / k g )}$ \\
\hline \multirow{2}{*}{ FLiBe } & Sanders, 1971 & 11.3 & 66 \\
& Holcomb, 2011 & 127 & 134 \\
FLiNaK & Andreades, 2015a & 176 & 176 \\
\hline
\end{tabular}

The more recent (2011 and 2015) cost estimates for enriched-Li FLiBe show an estimated cost around \$130$180 / \mathrm{kg}$ at $99.995 \%{ }^{7} \mathrm{Li}$. This is a significant increase over the 1971 (escalated) estimate of $\$ 66 / \mathrm{kg}$. Andreades (2015a) accounts for lithium enrichment by adding $\$ 97 / \mathrm{kg}$ for enrichment. This brings the $\mathrm{F}^{7} \mathrm{Li}(99.995 \%) \mathrm{Be}$ estimate to $\$ 194 / \mathrm{kg}$, with FLiNaK remaining at $\$ 270 / \mathrm{kg}$. This new estimate for unenriched FLiNaK is close to the 1971 estimate for enriched FLiNaK. Thus, a reasonable point estimate for enriched FLiBe is $\sim \$ 200 / \mathrm{kg}$, and for unenriched FLiNaK it is $\sim \$ 300 / \mathrm{kg}$.

The cost of enriched FLiBe is highly sensitive to the cost of enrichment. The Andreades (2015a) estimate of $\$ 97 / \mathrm{kg}$ could be low by an order of magnitude. Ault (2012) reports the cost of enrichment based on recent Chinese experience at $\$ 15,000 / \mathrm{kg}$ of enriched lithium $\left(99.995 \%{ }^{7} \mathrm{Li}\right)$ produced. Assuming $0.14 \mathrm{~kg}$ of lithium per $\mathrm{kg}$ of FLiBe, this puts the upper end cost of enriched FLiBe at approximately $\$ 2,000 / \mathrm{kg}$.

For comparison, 2008 estimates on the cost of heavy water gave a range of $\$ 300-600 / \mathrm{kg}$ (Canadian [CAD]) (Jackson, 2008). Translating this to US dollars (USD) with a 2008 exchange rate of $\sim 0.82 \mathrm{USD} / \mathrm{CAD}$, this is $\sim \$ 250-\$ 500 / \mathrm{kg}$. Escalating this to 2015 dollars gives a range of $\sim \$ 275-550 / \mathrm{kg}$.

\subsection{LICENSING}

Licensing costs are difficult to estimate. The FHR DR is not a commercial concept intended for long-term operation to provide electricity to the grid: it is a DR. The path and requirements to license a DR are clearly different, but they are not completely clear. Licensing costs of $\$ 150 \mathrm{M}$ are assumed for the FHR DR as an estimate with significant uncertainty. The costs related to licensing incurred by the designer are assumed to 
be included in the development and design costs. The FHR DR reactor system is relatively simple, but its supporting systems can be complex and expensive. Design costs are estimated at $\$ 300 \mathrm{M}$. The overall cost for first operation of the FHR DR is estimated to be $\$ 1.5 \mathrm{~B}$.

\subsection{SCHEDULE}

Historical experience with the construction of DOE research reactors, including HFIR, showed that the schedule for construction of existing research reactors ranges from 2 to 5 years. The Spallation Neutron Source (SNS) at ORNL is not a reactor, but it is a more complex FOAK facility. SNS had a construction time of 6 years. At the power reactor scale, the construction of the Summer and Vogtle AP-1000 power reactors are each taking on the order of 8 years. Thus, based on this experience, a reasonable estimate for the construction period for the FHR DR would be 4 to 5 years, with an initial estimate of 5 years.

The overall schedule to develop, design, and build the FHR DR is nominally 10 years. This is largely a function of design choices made primarily because they are near-term and relatively mature. However, it is important to consider issues with licensing and the uncertainties associated with the process and the timeline. The presumption is that the licensing effort will begin at initiation of the project and will take less than 10 years. Thus, development activities are assumed to lead to acceptable technology solutions within 3 to 5 years of initiation, and construction is assumed to be less than 5 years.

\section{REFERENCES}

Andreades, C., A. T. Cisneros, J. K. Choi, A. Y. K. Chong, M. Fratoni, S. Hong, L. R. Huddar, K. D. Huff, D. L. Krumwiede, M. R. Laufer, M. Munk, R. O. Scarlat, N. Zweibaum, E. Greenspan, and P. F. Peterson. Technical Description of the "Mark 1" Pebble-Bed Fluoride-Salt-Cooled High-Temperature Reactor (PB-FHR) Power Plant, University of California-Berkeley-UCBTH-14-002 (Berkeley, CA: University of California-Berkeley, 2014).

Andreades, C., and P. F. Peterson, "Mk1 Pebble-Bed Fluoride-Salt-Cooled High-Temperature Reactor Capital Cost Estimation," Transactions of the American Nuclear Society, 113 (2015a).

Andreades C., and P. F. Peterson, "Mk1 Pebble-Bed Fluoride-Salt-Cooled High-Temperature Reactor Operating Cost Estimation," Transactions of the American Nuclear Society, 113 (2015b).

Ault, T., K. Brozek et al., Lithium Isotope Enrichment: Feasible Domestic Enrichment Alternatives, UCBTH-12-005 (Berkeley, CA: University of California, Berkeley 2012).

Brown, N.R., et al., "Neutronic performance of uranium nitride composite fuels in a PWR," Nuclear Engineering and Design 275 (2014): 393-407.

Brown, N. R., M. Todosow, A. Cuadra, "Screening of advanced cladding materials and UN-U $\mathrm{Si}_{5}$ fuel," Journal of Nuclear Materials 462 (2015): 26-42.

Collin, B. P. AGR-1 Irradiation Test Final As-Run Report, INL/EXT-10-18097, Revision 3 (Idaho Falls, ID: Idaho National Laboratory, 2015).

Forsberg C., et al. Fluoride-salt-cooled High-Temperature Reactor for Power and Process Heat: Final Project Report, Massachusetts Institute of Technology-ANP-TR-157 (Cambridge, MA: Massachusetts Institute of Technology, December 2014a).

Forsberg, C., L.-W. Hu, J. Richard, R. Romatoski, B. Forget, J. Stempien, R. Ballinger, K. Sun, and D. Carpenter. Fluoride-Salt-Cooled High-Temperature Test Reactor (FHTR): Goals, Options, Ownership, Requirements, Design, Licensing, and Support Facilities, Massachusetts Institute of Technology-ANPTR-154 (Cambridge, MA: Massachusetts Institute of Technology, December 2014b). 
Forsberg, C., D. Curtis, J. Stempien, R. MacDonald, P. Peterson. Fluoride-Salt-Cooled High-Temperature Reactor (FHR) Commercial Basis and Commercialization Strategy, Massachusetts Institute of Technology-ANP-TR-153 (Cambridge, MA: Massachusetts Institute of Technology, December 2014c).

George N. M., et al. "Neutronic analysis of candidate accident-tolerant cladding concepts in pressurized water reactors," Annals of Nuclear Energy 75(2015): 703-712.

Greene, S. R., et al. Pre-Conceptual Design of a Fluoride-Salt-Cooled Small Modular Advanced highTemperature Reactor (SmAHTR), ORNL/TM-2010/199 (Oak Ridge, TN: UT-Battelle, LLC, Oak Ridge National Laboratory, 2010).

Holcomb, D. E., F. J. Peretz, and A. L. Qualls. Advanced High Temperature Reactor Systems and Economic Analysis, ORNL/TM-2011/364 (Oak Ridge, TN: UT-Battelle, LLC, Oak Ridge National Laboratory, September 2011a).

Holcomb D. E., et al. Core and Refueling Design Studies for the Advanced High Temperature Reactor, ORNL/TM-2011/365 (Oak Ridge, TN: UT-Battelle, LLC, Oak Ridge National Laboratory, September 2011b).

Holcomb, D. E., G. F. Flanagan, G. T. Mays, W. D. Pointer, K. R. Robb, and G. L. Yoder, Jr. Fluoride SaltCooled High-Temperature Reactor Technology Development and Demonstration Roadmap, ORNL/TM2013/401 (Oak Ridge, TN: UT-Battelle, LLC, Oak Ridge National Laboratory, September 2013).

Ilas, D., J. C. Gehin, and S. R. Greene. "Preliminary Nuclear Design Studies for a Small Modular Advanced High Temperature Reactor (SmAHTR),” Trans. Am. Nucl. Soc. 103 (2010): 607-608.

Jackson, D., "Is There Enough Heavy Water For More CANDU Reactors?" Reactors Canada (May 21, 2008): http://reactorscanada.com/2008/05/21/is-there-enough-heavy-water-for-more-candu-reactors/, accessed January 30, 2016.

Kingsbury, C. W., "Fuel Cycle Cost and Fabrication Model for Fluoride Salt High Temperature Reactor (FHR) 'Plank' Fuel Design Optimization” (master's thesis, Georgia Institute of Technology, 2015).

MYRRHA Home, http://myrrha.sckcen.be/en, accessed January 30, 2016.

NEI (Nuclear Energy Institute), http://www.nei.org, accessed January 30, 2016.

Petti, D., "An Overview of the DOE Advanced Gas Reactor Fuel Development and Qualification Program" (presentation, Massachusetts Institute of Technology, 2006).

Powers, J., “TRISO Fuel Performance: Modeling, Integration into Mainstream Design Studies, and Application to a Thorium-fueled Fusion-Fission Hybrid Blanket" (Ph.D. dissertation, University of California, Berkeley, 2011).

Powers, J. J., "Fully Ceramic Microencapsulated Fuel in FHRs: A Preliminary Reactor Physics Assessment," Trans. Am. Nucl. Soc 111 (2014): 1196-1199.

Rosner, R., S. Goldberg, J. S. Hezir, "Small Modular Reactors-Key to Future Nuclear Power Generation in the U.S.," The University of Chicago Technical Report (2011).

Sanders, J. P., A Review of Possible Choices for Secondary Coolants for Molten Salt Reactors, ORNL CF71-8-10 (Oak Ridge, TN, Oak Ridge National Laboratory, 1971).

Scarlat R., et al., "Design and licensing strategies for the fluoride-salt-cooled, high-temperature reactor (FHR) technology," Progress in Nuclear Energy 77 (2014): 406-420.

Shropshire, D. E., K. A. Williams, J. D. Smith, B. W. Dixon, M. Dunzik-Gougar, R. D. Adams, D. Gombert, J. T. Carter, E. Schneider, D. Hebditch, Advanced Fuel Cycle Cost Basis, INL/EXT-07-12107 Rev 2 (Idaho Falls, ID, Idaho National Laboratory, 2009). 
Stempien, J. D., R. G. Ballinger, C. W. Forsberg, "A Model of Tritium Transport and Corrosion in SaltCooled Reactors," Transactions of the American Nuclear Society Winter Meeting, 15081, Washington, DC, November 8-12, 2015.

Strasser, A. J., J. Santucci, K. Lindquist, W. Yario, G. Stern, L. Goldstein, and L. Joseph. An Evaluation of Stainless Steel Cladding for Use in Current Design LWRs, NP-2642 (Palo Alto, CA, Electric Power Research Institute, 1982).

Tennessee Valley Authority, letter from TVA to NRC, "Watts Bar Nuclear Plant, Unit 1 Tritium Production Program, Updated Plans for Cycle 13 Operation and Updated Evaluation of the Radiological Impacts of Tritium Permeation into the Reactor Coolant System,” January 30, 2015.

Terrani, K. A., L. L. Snead, L. L., J. C. Gehin, "Microencapsulated fuel technology for commercial light water and advanced reactor application," J. Nucl. Mater. 427 (2012): 209-224.

Waltar, A. E., D. R. Todd, P. V. Tsvetkov, Fast Spectrum Reactors (New York: Springer, 2012).

White, J. T., A. T. Nelson, D. D. Byler, D. J. Safarik, J. T. Dunwoody, and K. J. McClellan, "Thermophysical properties of U 3 Si 5 to 1773K," Journal of Nuclear Materials 456 (2015): 442-448.

Wigeland, R., T. Taiwo, H. Ludewig, M. Todosow, W. Halsey, J. Gehin, R. Jubin, J. Buelt, S. Stockinger, K. Jenni, B. Oakley, Nuclear Fuel Cycle Evaluation and Screening-Final Report, INL/EXT-14-31465 FCRD- FCO-2014-000106 (Idaho Falls, ID, Idaho National Laboratory, October 8, 2014).

WISE (World Information Service on Energy) Uranium Project, Nuclear Fuel Cost Calculator, http://www.wise-uranium.org/nfcc.html, accessed on January 30, 2016.

Yang, H., "Economic Essues (sic) of Fast Reactor in China" (presentation, Technical Meeting on Fast Reactors and Related Fuel Cycle Facilities with Improved Economic Characteristics, Vienna, Austria, September 12, 2013).

Varma V. K., et al., AHTR Mechanical, Structural, and Neutronic Preconceptual Design, ORNL/TM2012/320 (Oak Ridge, TN, Oak Ridge National Laboratory, October, 2012). 



\section{APPENDIX A. FHR DR SCORING \\ GOAL 1: DEMONSTRATION REACTOR SIGNIFICANTLY ADVANCES THE TECHNOLOGY TOWARD A POTENTIAL FOAK PLANT}

\section{CRITERION 1.1: CAPABILITY TO DEMONSTRATE SAFETY BEHAVIOR OF COMMERCIAL SYSTEM}

\subsection{1: Does the demonstration system have safety characteristics systems/components expected in the commercial plant?}

The FHR DR replicates the safety characteristics and has prototypic systems and components expected in a commercial plant. These include high boiling temperature and low pressure coolant, large operating margin for allowable fuel temperature during anticipated occurrences and accident sequences, inherently negative reactivity coefficients in the core design (including void coefficient), active and passive decay heat removal systems, and redundant and diverse shutdown systems. The reactor building is equipped with tritium monitoring and management systems that reduce the release of tritium to the environment to allowable levels.

\section{CRITERION 1.2: DETAILED INSTRUMENTATION AND DATA FOR CODE VALIDATION TESTS}

\subsection{1: Does the design have adequate instrumentation and will it gather appropriate data for code validation tests?}

The FHR DR will serve as a demonstration testbed for commercial technologies. These technologies will be instrumented for high resolution spatial and dynamic response. For pumps and reactivity control drives, temperature, electrical and mechanical sensors will gather data on performance for comparison to performance prediction codes. Neutronic measurements will spatially resolve reactor core response to reactivity control actions.

The FHR DR passive DRACS contains instrumentation packages that allow the behavior of that system to be fully characterized. The collected data will relate ambient environmental conditions to temperature and flow conditions within the reactor vessel and within the passive DRACS system so that detailed analysis of system performance can be used to design and license passively safe commercial concepts using the collected data.

\section{CRITERION 1.3: SCALABLE TECHNOLOGY OPTIONS}

\subsection{1: Does the design implement technology selections that are prototypic or scalable to a commercial unit?}

The technologies used in the FHR DR are prototypic and at scale (similar in size to the SmAHTR) or scalable (using the AHTR as a reference) to commercial units. The major systems include vessel and piping fabrication, fuel fabrication and use, heat exchanger design, pump technology, instrumentation and reactor facility systems including tritium management. 


\section{CRITERION 1.4: SCALABLE MAINTENANCE TECHNIQUES AND SCHEDULES}

\subsection{1: Does the design have maintenance approaches that are prototypic or scalable to commercial units?}

The FHR DR will use components and configurations that are directly applicable to commercial systems. One example is a spent fuel handling system that is prototypic and scalable to the AHTR and similar to several liquid metal-cooled advanced reactor concepts. A key performance issue is the use of remote maintenance activities that limit the need for human intention on most if not all anticipated routine maintenance activities. Modern techniques and capabilities developed and demonstrated for target replacement on the SNS will be incorporated into the final FHR DR design. Specifically, fuel handling and pump removal and replacement are targeted for remote maintenance demonstration in the FHR DR.

\section{CRITERION 1.5: SCALABLE FABRICATION OPTIONS}

\subsection{1: Does the design use prototypic or scalable technologies in the fabrication of important systems and components?}

The reactor vessel incorporates a code-approved alloy $(800 \mathrm{H})$ with a protective nickel-based liner material. Techniques to facilitate this material combination and to fabricate components from it will be examined to ensure that structural material fabrication methods used for the FHR DR are applicable to commercial FHR concepts.

The fuel assembly is prototypic and scalable to the SmAHTR concept, which could use either plank fuel forms or prismatic block fuel forms. The FHR DR fuel assembly is also directly prototypic and scalable to the AHTR concept. The AHTR system will require stacks of FHR DR fuel assembly blocks to form a complete core, and the details of this stacking require additional investigation. However, other advanced reactor concepts have already begun to examine the feasibility of self-aligning structural fuel assembly designs, and the results are directly applicable to the FHR.

PROPOSED GOAL 1 SCORES FOR THE FHR DR

\begin{tabular}{|c|c|c|c|c|}
\hline 1.1.1 & $\begin{array}{l}\text { Does the demonstration } \\
\text { system have safety } \\
\text { characteristics and } \\
\text { systems/components } \\
\text { expected in the commercial } \\
\text { plant? }\end{array}$ & $\begin{array}{l}\text { Demo replicates the } \\
\text { safety characteristics } \\
\text { and has prototypic } \\
\text { systems/components }\end{array}$ & $\begin{array}{l}\text { Safety behavior of } \\
\text { Demo can be } \\
\text { confidently scaled } \\
\text { to the commercial } \\
\text { system }\end{array}$ & $\begin{array}{l}\text { Safety behavior of } \\
\text { Demo has important } \\
\text { non-prototypic } \\
\text { aspects }\end{array}$ \\
\hline 1.2.1 & $\begin{array}{l}\text { Does the design have } \\
\text { adequate instrumentation } \\
\text { and will it gather } \\
\text { appropriate data for code } \\
\text { validation tests? }\end{array}$ & $\begin{array}{l}\text { Adequate } \\
\text { instrumentation and } \\
\text { data to scale } \\
\text { behavior and } \\
\text { validate performance } \\
\text { and safety codes }\end{array}$ & $\begin{array}{l}\text { Some } \\
\text { instrumentation and } \\
\text { data to scale } \\
\text { behavior and } \\
\text { validate } \\
\text { performance and } \\
\text { safety codes }\end{array}$ & $\begin{array}{l}\text { Limited } \\
\text { instrumentation and } \\
\text { data to scale behavior } \\
\text { and validate } \\
\text { performance and } \\
\text { safety codes }\end{array}$ \\
\hline 1.3.1 & $\begin{array}{l}\text { Does the design implement } \\
\text { technology selections that } \\
\text { are prototypic or scalable to } \\
\text { commercial unit? }\end{array}$ & Prototypic \& at scale & $\begin{array}{l}\text { Prototypic \& } \\
\text { scalable }\end{array}$ & $\begin{array}{l}\text { Not prototypic or not } \\
\text { at scale }\end{array}$ \\
\hline 1.4.1 & $\begin{array}{l}\text { Does the design have } \\
\text { maintenance approaches } \\
\text { that are prototypic or } \\
\text { scalable to commercial unit? }\end{array}$ & Prototypic \& at scale & $\begin{array}{l}\text { Prototypic \& } \\
\text { scalable }\end{array}$ & $\begin{array}{l}\text { Not prototypic or not } \\
\text { at scale }\end{array}$ \\
\hline
\end{tabular}




\begin{tabular}{|c|c|c|c|c|}
\hline 1.5.1 & $\begin{array}{l}\text { Does the design use } \\
\text { prototypic or scalable } \\
\text { technologies in the } \\
\text { fabrication of important } \\
\text { systems and components? }\end{array}$ & Prototypic \& at scale & $\begin{array}{l}\text { Prototypic \& } \\
\text { scalable }\end{array}$ & $\begin{array}{l}\text { Not prototypic or not } \\
\text { at scale }\end{array}$ \\
\hline
\end{tabular}

\section{GOAL 2: DEMO REACTOR OPERATIONS HELP RESOLVE TECHNICAL BARRIERS (E.G., PREDICTABILITY) TO ADVANCE REACTOR ECONOMICS AND RELIABILITY}

\section{CRITERION 2.1: PROJECT COSTS AND SCHEDULE}

\subsection{1: Project costs}

Tritium handling system development and demonstration, although leveraged against other DOE programs, will also be a significant effort. Qualification of materials and processes, development of remote maintenance capability, and code development, verification, and validation are well understood activities, but they will still require significant investment. If these activities are assumed to cost $\$ 5 \mathrm{M}$ each over the course of the 10 -year effort to operation, each would cost $\$ 50 \mathrm{M}$, placing total FHR DR development costs at $\$ 450 \mathrm{M}$.

For the purposes of this effort, a capital cost of $\$ 500 \mathrm{M}$ above the mean of the cost range is assumed until more design detail is available to produce a better estimate. When combined with the estimates for the development cost, design cost, licensing cost, and salt procurement cost, the extrapolated project cost estimate is approximately $\$ 1.5$ billion. However, there is notable uncertainty in this estimate, and additional licensing costs, design costs, and indirect costs may be possible. In spite of the uncertainty, the FHR DR is a technology testbed which we expect could be built for significantly less than $\$ 4$ billion.

\subsection{2: Project schedule}

The FHR DR can be operational within 10 years of a DOE CD-0 decision to proceed. This estimate assumes that focused research and development will continue within the national laboratory and university systems and that it will be complemented with new, necessary separate effects development and testing to begin immediately after the decision to proceed. Data from these larger scale projects will begin to inform preliminary design efforts within 2 or 3 years of being commissioned. The construction period is expected to range from for years (comparable to that of HFIR) to seven years (similar to that of large commercial LWRs). It is recognized that this is an aggressive schedule, and that a 10-15 year schedule may also be possible. However, the FHR DR is designed to be licensable as a test reactor.

\section{CRITERION 2.2: OPERATIONAL COSTS AND SCHEDULE}

\subsection{1: Annual operation costs}

The estimated operating costs of the FHR DR range from $\$ 62 / \mathrm{MWt}-\mathrm{h}$ with electricity sales to $\$ 91 / \mathrm{MWt}-\mathrm{h}$ with no electricity sales 


\section{CRITERION 2.3: RELIABILITY OF OPERATIONS}

\subsection{1: Availability factor}

The FHR DR is anticipated to operate for $8-18$ months, depending on configuration, with a one-month outage if a single-batch fuel cycle is implemented. Assuming a longer 50-day outage and 18-month cycle, the attainable availability during normal operation is greater than $90 \%$.

\section{PROPOSED GOAL 2 SCORES FOR THE FHR DR}

\begin{tabular}{lllll}
\hline $\mathbf{2 . 1 . 1}$ & Project cost & $<\mathbf{4} \mathbf{B} \$$ & $4-8 \mathrm{~B} \$$ & $>8 \mathrm{~B} \$$ \\
$\mathbf{2 . 1 . 2}$ & Project schedule & $<\mathbf{1 0}$ years & $10-15$ years & $>15$ years \\
$\mathbf{2 . 2 . 1}$ & Annual operating costs & $<\$ 0 /$ MWt $\mathrm{h}$ & $\$ 0-10 / \mathrm{MWt}-\mathrm{h}$ & $>\mathbf{\$ 1 0} / \mathbf{M W t}-\mathbf{h}$ \\
$\mathbf{2 . 3 . 1}$ & Availability factor & $\mathbf{> 0 \%} \%$ & $70-90 \%$ & $<70 \%$ \\
\hline
\end{tabular}

\section{GOAL 3: DEMONSTRATION REACTOR HAS A ROBUST SAFETY DESIGN BASIS FOR LICENSING}

\section{CRITERION 3.1: LICENSED BY THE NUCLEAR REGULATORY COMMISSION}

\subsection{1: Ability to address key licensing issues for follow-on commercial units}

The likely path would be for DOE to either (1) cede the certification (or licensing) to NRC, or (2) contract $\mathrm{NRC}$ to review the certification package against the requirements of RG1.70 as stipulated by 10CFR830. The FHR DR includes all key technologies, components, and operation conditions that represent commercial follow-on systems and therefore will provide the ability to address key licensing issues including tritium management, passive safety, and overall plant operation.

\subsection{2: Size of emergency planning zone}

The size of the emergency planning zone is less than 400 meters.

PROPOSED GOAL 3 SCORES FOR THE FHR DR

\begin{tabular}{lllll}
\hline 3.1.1 & $\begin{array}{l}\text { Ability to address key } \\
\text { licensing issues for } \\
\text { follow-on commercial } \\
\text { units }\end{array}$ & $\begin{array}{l}\text { Demonstration unit } \\
\text { can address most of } \\
\text { the key licensing } \\
\text { issues for follow-on } \\
\text { commercial units }\end{array}$ & $\begin{array}{l}\text { Demonstration unit can } \\
\text { address some of key } \\
\text { licensing issues for } \\
\text { follow-on commercial } \\
\text { units }\end{array}$ & $\begin{array}{l}\text { Demonstration unit can } \\
\text { address few number of key } \\
\text { licensing issues for follow- } \\
\text { on commercial units }\end{array}$ \\
\cline { 2 - 5 } $\begin{array}{l}\text { Size of emergency } \\
\text { planning zone }\end{array}$ & $<\mathbf{4 0 0 ~} \mathbf{m}$ & $0.4-16 \mathrm{~km}$ & $16 \mathrm{~km}$ \\
\hline
\end{tabular}

\section{GOAL 4: DEMONSTRATION REACTOR SUPPORTS DEMONSTRATION OF TECHNOLOGY AND SYSTEM INTEGRATION (ENHANCING IMMEDIATE, INTERMEDIATE AND LONG-TERM VALUE OF THE PROJECT)}

\section{CRITERION 4.1: FACILITATE COMPONENT DEMONSTRATION}

4.1.1: Does the system facilitate component demonstration of that expected in follow-on commercial units? 
The relevant commercial applications of the fixed fuel FHR are the SmAHTR and the AHTR designs. The technologies proposed for the FHR DR are directly applicable to these designs. They are prototypic and at scale for the SmAHTR concept (3) and prototypic and scalable (2) for the larger AHTR concept. Instrumentation, heat exchangers, pumps, and control drive mechanisms are directly relevant to all FHR commercial concepts.

\section{CRITERION 4.2: DEMONSTRATE ALTERNATE CORE CONFIGURATIONS AND FUEL TYPES}

\subsection{1: Number of alternative core configurations}

The number of alternative core configurations is greater than two. The reference baseline FHR DR used hexagonal prismatic blocks that have the same outer dimensions as the SmAHTR concept. A change to this or another similar sized hexagonal fuel assembly is straightforward. The FHR DR vessel design accommodates removal and replacement of the core support structure so that other fuel forms and cores could be tested within the facility.

\subsection{2: Number of alternative fuel types?}

The number of alternative fuel types is greater than two. TRISO fuels have been evaluated and are acceptable. Other fuel materials and forms were preliminarily reviewed and deemed acceptable neutronically. These fuels forms specifically used pellets within cladding, and the cladding materials (SiC and molybdenum based systems) require additional development. However, once matured, these cores could be operated in the FHR DR.

\section{CRITERION 4.3: R\&D REQUIRED BEFORE DEMONSTRATION REACTOR CONSTRUCTION/OPERATION}

\subsection{1: Research and development time}

Research and development time is between 5 and 10 years. Some basic research related to FHR operation remains to be conducted, and the results of this basic research will require demonstration in moderately scaled loops. The primary example of this is salt chemistry control and its impact on structural material interactions. Usable data from the scaled test loops may not be available within 5 years of project initiation and could thus impact final design until then. Technologies required for the FHR DR would be developed and demonstrated beginning immediately in the project and would continue until final component design. The FHR DR fuel is relatively mature. Thus, the major components to be developed include control drive mechanisms, pumps and heat exchangers.

Tritium management techniques must also be developed and demonstrated beginning, at the small laboratory scale and progressing through credible reactor relevant demonstrations. Significant effort has been underway for many years in conjunction with the ITER project, and those tritium management data and protocols will be followed for the FHR DR to the degree possible.

\subsection{2: Research and development costs}

Research and development costs will be between $\$ 250 \mathrm{M}$ and $\$ 500 \mathrm{M}$. For each of the three major components to be developed and demonstrated, a development cost on the order of $\$ 50 \mathrm{M}$ is anticipated. The cost of tritium management will be leveraged against other DOE programs; however, the specific cost associated with tritium management in the FHR DR can also be reasonably estimated to cost $\$ 50 \mathrm{M}$. 
Code development, verification, and validation can be expected to place total development costs over \$350M.

\section{CRITERION 4.4: PROVIDE ABILITY TO CONDUCT IRRADIATIONS OF MATERIALS AND FUELS UNDER PROTOTYPICAL CONDITIONS.}

\subsection{1: Fast flux conditions}

FHRs are graphite moderated thermal reactors. The peak fast flux (greater than $0.1 \mathrm{MeV}$ ) is $1.25 \times 10^{14} \mathrm{n} / \mathrm{cm}^{2}$-s.

\subsection{2: Thermal flux conditions $(0.625 \mathrm{eV})$}

The peak thermal $(\mathrm{E}<0.625 \mathrm{eV})$ flux is $\mathbf{2 . 5} \times \mathbf{1 0}^{\mathbf{1 4}} \mathbf{n} / \mathbf{c m}^{\mathbf{2}}$-s.

\subsection{3: Irradiation volume and length}

The total irradiation volume of the baseline configuration is 30 liters. The FHR DR is reconfigurable, and other core configurations may have a different irradiation volumes. The length is anticipated to be on the order of three meters based on the current configuration.

PROPOSED GOAL 4 SCORES FOR THE FHR DR

\begin{tabular}{|c|c|c|c|c|}
\hline 4.1.1 & $\begin{array}{l}\text { Does the system facilitate } \\
\text { component demonstration of } \\
\text { that expected in follow-on } \\
\text { commercial units? }\end{array}$ & $\begin{array}{l}\text { Prototypic \& at } \\
\text { scale }\end{array}$ & Prototypic \& scalable & $\begin{array}{l}\text { Not prototypic or not at } \\
\text { scale }\end{array}$ \\
\hline 4.2.1 & $\begin{array}{l}\text { Number of alternative core } \\
\text { configurations }\end{array}$ & More than 2 & $1-2$ & None \\
\hline 4.2.2 & $\begin{array}{l}\text { Number of alternative fuel } \\
\text { types }\end{array}$ & More than 2 & $1-2$ & None \\
\hline 4.3.1 & R\&D Time & $<5$ years & 5-10 years & $>10$ years \\
\hline 4.3.2 & R\&D Cost & $<250 \mathrm{M} \$$ & 250-500 M\$ & $>500 \mathrm{M} \$$ \\
\hline 4.4 .1 & Fast flux conditions & $>5 \mathrm{E} 15 \mathrm{n} / \mathrm{cm}^{2}-\mathrm{s}$ & $5 \mathrm{E} 14$ to $5 \mathrm{E} 15 \mathrm{n} / \mathrm{cm}^{2}-\mathrm{s}$ & $<5 E 14 \mathrm{n} / \mathrm{cm}^{2}-\mathrm{s}$ \\
\hline 4.4.2 & $\begin{array}{l}\text { Thermal flux conditions } \\
(<0.625 \mathrm{eV})\end{array}$ & $>5 \mathrm{E} 14 \mathrm{n} / \mathrm{cm}^{2}-\mathrm{s}$ & $\begin{array}{l}\text { 1E14 to } 5 \mathrm{E} 14 \mathrm{n} / \mathrm{cm}^{2}- \\
\text { s }\end{array}$ & $<1 \mathrm{E} 14 \mathrm{n} / \mathrm{cm}^{2}-\mathrm{s}$ \\
\hline 4.4.3 & Irradiation volume and length & $\begin{array}{l}\text { Vol }>10 \text { liters, } \\
\text { length }>2 \mathrm{~m}\end{array}$ & $\begin{array}{l}\text { Vol }=5-10 \text { liters, } \\
\text { length }=0.5-2.0 \mathrm{~m}\end{array}$ & $\begin{array}{l}\text { Vol }<5 \text { liters, length }< \\
0.5 \mathrm{~m}\end{array}$ \\
\hline
\end{tabular}




\section{GOAL 5: DEMONSTRATE FUEL CYCLE OF ADVANCED REACTOR}

\section{CRITERION 5.1: ABILITY TO DEMONSTRATE UTILIZATION OF NATURAL RESOURCES}

\subsection{1: Use of fuel natural resources}

The best natural resource utilization for a single-batch FHR DR fuel cycle is $320 \mathrm{t} / \mathrm{GWe}-\mathrm{yr}$, corresponding to a 549-day single batch cycle length with a $90 \%$ capacity factor.

\section{CRITERION 5.2: PROTOTYPIC FUEL FABRICATION}

\subsection{1: Is the fuel fabrication approach prototypic or scalable to a commercial unit?}

The fuel fabrication approach is prototypic and scalable. Fuel compact fabrication is directly prototypic to commercial applications using TRISO fuels in prismatic assemblies. The FHR DR fuel fabrication approach is directly prototypic and scalable to the AHTR, and the FHR DR can accommodate other hexagonal fuel forms if they are available.

\section{CRITERION 5.3: PROTOTYPIC FUEL PERFORMANCE}

\subsection{1: Is the anticipated fuel performance prototypic or scalable to commercial unit?}

The anticipated fuel performance is prototypic and at scale. The FHR DR TRISO fuel performance is within the envelope of the AHTR and SmAHTR designs. Therefore, it is both prototypic and at scale relative to FHR commercial concepts.

\section{CRITERION 5.4: SPENT FUEL HANDLING}

\subsection{1: Is the spent fuel handling prototypic or scalable to commercial unit?}

The spent fuel handling is prototypic and at scale. The methodology proposed for spent fuel handling is consistent with that proposed for the AHTR and incorporates features of both the PRISM concept (storing elements within the vessel boundary) and gas reactor concepts (pulling fuel from the vessel and moving it through a progression to eventual dry storage in stainless steel canisters).

PROPOSED GOAL 5 SCORES FOR THE FHR DR

\begin{tabular}{|c|c|c|c|c|}
\hline 5.1 .1 & Use of fuel natural resources & $<20 \mathrm{MT} / \mathrm{GWe}-\mathrm{yr}$ & 20-150 MT/GWe-yr & $>150 \mathrm{MT} / \mathrm{GWe}-\mathrm{yr}$ \\
\hline 5.2 .1 & $\begin{array}{l}\text { Is the fuel fabrication approach } \\
\text { prototypic or scalable to } \\
\text { commercial unit? }\end{array}$ & Prototypic \& at scale & $\begin{array}{l}\text { Prototypic \& } \\
\text { scalable }\end{array}$ & $\begin{array}{l}\text { Not prototypic or not at } \\
\text { scale }\end{array}$ \\
\hline 5.3.1 & $\begin{array}{l}\text { Is the anticipated fuel } \\
\text { performance prototypic or } \\
\text { scalable to commercial unit? }\end{array}$ & $\begin{array}{l}\text { Prototypic \& at } \\
\text { scale }\end{array}$ & Prototypic \& scalable & $\begin{array}{l}\text { Not prototypic or not at } \\
\text { scale }\end{array}$ \\
\hline 5.4 .1 & $\begin{array}{l}\text { Is the spent fuel handling } \\
\text { prototypic or scalable to } \\
\text { commercial unit? }\end{array}$ & $\begin{array}{l}\text { Prototypic \& at } \\
\text { scale }\end{array}$ & Prototypic \& scalable & $\begin{array}{l}\text { Not prototypic or not at } \\
\text { scale }\end{array}$ \\
\hline
\end{tabular}




\section{CRITERION 6.1: DEMONSTRATE INTEGRATION WITH VARIOUS ENERGY CONVERSION SYSTEMS OR INDUSTRIAL APPLICATIONS}

\subsection{1: Number of energy conversion systems or industrial applications?}

The number of energy conversion systems or industrial applications is greater than three. The FHR DR concept produces high temperature heat energy at low pressure. The reference baseline use of the FHR DR is high efficiency electricity generation by coupling the system to an open-air Brayton cycle.

However, the FHR DR incorporates a small salt vat energy storage system (similar to that proposed for the SmAHTR), and energy from it can be directed in a number of ways, including heat extraction to drive chemical processes (such as the production of hydrogen), heat extraction to drive physical processes (such as the Red Leaf process for shale oil extraction), or a combination of using high temperature heat for an initial process, while the remaining lower temperature heat can be used to drive steam-based electricity generation.

\section{CRITERION 6.2: CAPTURE LARGE AND DIVERSE PORTOFILIO OF INDUSTRIAL PROCESS HEAT APPLICATIONS}

\subsection{1: Coolant outlet temperature}

The FHR DR outlet temperature is greater than $700{ }^{\circ} \mathrm{C}$.

PROPOSED GOAL 6 SCORES FOR THE FHR DR

\begin{tabular}{lllll}
\hline 6.1.1 & $\begin{array}{l}\text { Number of energy conversion } \\
\text { systems or industrial } \\
\text { applications }\end{array}$ & More than $\mathbf{3}$ & $1-3$ & None \\
\hline $\mathbf{6 . 2 . 1}$ & Coolant outlet temperature & $>\mathbf{7 0 0}{ }^{\circ} \mathbf{C}$ & $400-700{ }^{\circ} \mathrm{C}$ & $<400{ }^{\circ} \mathrm{C}$ \\
\hline
\end{tabular}

